\title{
Robust intermodal hub location under polyhedral demand uncertainty
}

\author{
Merve Meraklı, Hande Yaman* \\ Department of Industrial Engineering, Bilkent University, Ankara, Turkey
}

\section{A R T I C L E I N F O}

\section{Article history:}

Received 16 June 2015

Revised 21 January 2016

Accepted 21 January 2016

Available online 12 February 2016

\section{Keywords:}

Hub location

Multiple allocation

Demand uncertainty

Robustness

Hose model

Benders decomposition

\begin{abstract}
A B S T R A C T
In this study, we consider the robust uncapacitated multiple allocation $p$-hub median problem under polyhedral demand uncertainty. We model the demand uncertainty in two different ways. The hose model assumes that the only available information is the upper limit on the total flow adjacent at each node, while the hybrid model additionally imposes lower and upper bounds on each pairwise demand. We propose linear mixed integer programming formulations using a minmax criteria and devise two Benders decomposition based exact solution algorithms in order to solve large-scale problems. We report the results of our computational experiments on the effect of incorporating uncertainty and on the performance of our exact approaches.
\end{abstract}

(c) 2016 Elsevier Ltd. All rights reserved.

\section{Introduction}

Hubs are facilities that consolidate and distribute flow from many origins to many destinations. Hub structure is common in transportation networks that benefit from economies of scale such as airline and cargo delivery networks. Many variants of hub location problems have been studied in the last few decades. The $p$-hub median problem is one of the most studied problems in the hub location literature. In the $p$-hub median problem, the aim is to locate $p$ hubs and to route the flow between origin-destination pairs through these hubs so that the total transportation cost is minimized. Direct shipments between nonhub nodes are usually not allowed. There are variants of the problem where a nonhub node can send and receive traffic through all hubs and others where there is a restriction on the number of hubs that a nonhub node can be connected to. The former is known as the multiple allocation setting. In some other variants, hub or edge capacities are imposed. In this paper, we study an uncapacitated $p$-hub median problem with multiple allocation and no direct shipments. In the $p$-hub median problem, the routing cost between two hub nodes is discounted independently of the amount of flow travelling between these two hubs. For this reason, this problem may not model the discounts due to economies of scale correctly. On the other hand, it has applications in intermodal transportation where discounts on hub-to-hub transfers apply due to the use of a cheaper transportation mode such as rail or maritime transportation.

An important issue that arises while designing a hub network is coping with the uncertainty in the data. The $p$-hub median problem is solved in the strategic planning phase, usually before actual point-to-point demand values are realized and the network starts operating. The demand may have large variations depending on the seasons, holidays, prices, level

\footnotetext{
* Corresponding author. Tel.: +90 3122902768.

E-mail addresses: merakli@bilkent.edu.tr (M. Meraklı), hyaman@bilkent.edu.tr (H. Yaman).
} 
of economic activities, population, service time and quality and the price and quality of the services provided by the competitors. A decision made based on a given realization of the data may be obsolete in time of operation.

The uncertainty in the demand values can be modeled in various forms: (i) the probability distribution of demand values may be known; (ii) the probability distribution may not be known but demands can take any value in a given set; (iii) a discrete set of possible scenarios may be identified. In this study, we model uncertainty with a polyhedral set. More precisely, we consider the hose model and its restriction with box constraints. The hose model has been introduced by Duffield et al. (1999) and Fingerhut et al. (1997) to model demand uncertainty in virtual private networks. In the hose model, the user specifies aggregate upper bounds on inbound and outbound traffic of each node. Modeling uncertainty with this model has several advantages. First, it is simpler to estimate a value for each node compared to for each node pair. Second, it has resource-sharing flexibility. Third, it is less conservative compared to a model in which each origin-destination demand is set to its worst case value. Finally, it has the advantage of reducing statistical variability through aggregation. Still, the hose model contains extreme scenarios in which few origin destination pairs may have large traffic demands and remaining pairs may have zero traffic. To consider more realistic situations, Altın et al. (2011a) propose to use a hybrid model where lower and upper bounds on individual traffic demands are added to the hose model. This requires estimation of bounds for each node pair but leads to less conservative solutions. These uncertainty models are suitable for transportation applications where pairwise demands are often estimated based on factors such as the population, level of economic activity and access to transportation infrastructure at origins and destinations (see, e.g., Bhadra, 2003 who examines the relationship between origin and destination travel and local area characteristics and Hsiao and Hansen, 2011). The hose model is a simple way of modeling correlations such as a person flying from Istanbul to Paris is not flying at the same time from London to Istanbul.

To hedge against uncertainty in the demand data, we adopt a minmax robustness criterion and minimize the cost of the network under the worst case scenario. In robust optimization, commonly, one does not make assumptions about the probability distributions, rather assumes that the data belongs to an uncertainty set. A robust solution is one whose worst case performance over all possible realizations in the uncertainty set is the best (see, e.g., Atamtürk, 2006; Ben-Tal et al., 2004; Ben-Tal and Nemirovski, 1998, 1999, 2008; Bertsimas and Sim, 2003, 2004; Mudchanatongsuk et al., 2008; Ordóñez and Zhao, 2007; Yaman et al., 2001, 2007b).

In this study, we introduce the robust multiple allocation $p$-hub median problem under hose and hybrid demand uncertainty. Our contribution is to incorporate demand uncertainty into a classical problem and to investigate the gain of recognizing the uncertainty. We derive mixed integer programming formulations and propose exact solution methods based on Benders decomposition. In our computational experiments, we first analyze the changes in cost and hub locations with different uncertainty sets. Then we test the limits of solving the model with an off-the-shelf solver and compare the performances of two decomposition approaches. Our computational experiments showed that the decomposition algorithms are able to solve large instances that cannot be solved with an off-the-shelf solver and that it is possible to obtain significant cost savings in case of demand fluctuations by incorporating uncertainty into the decision making process.

The rest of the paper is organized as follows. In Section 2, we review the related studies in the literature. In Section 3, we introduce the robust multiple allocation $p$-hub median problem under hose and hybrid demand uncertainty and propose mixed integer programming formulations. We devise two different Benders decomposition based exact solution algorithms in Section 4 and report our computational findings in Section 5. We conclude in Section 6.

\section{Literature review}

Hub location has grown to be an important and well-studied area of network analysis. Detailed surveys of studies on hub location are given in Campbell (1994b), O'Kelly and Miller (1994), Klincewicz (1998), Campbell et al. (2002), Alumur and Kara (2008), Campbell and O'Kelly (2012) and Farahani et al. (2013).

Here we review first the studies on the uncapacitated multiple allocation $p$-hub median problem (UMApHMP) and then the studies on hub location problems under data uncertainty.

UMApHMP is first formulated by Campbell (1992). Alternative formulations with four index variables are given by Campbell (1994a) and Skorin-Kapov et al. (1996). Ernst and Krishnamoorthy (1998a) propose a three-indexed formulation based on aggregated flows. Various exact and heuristic solution algorithms are devised to solve UMApHMP efficiently (see, e.g., Campbell, 1996; Ernst and Krishnamoorthy, 1998a; 1998b). Besides, the variant of the problem where the number of hubs is not fixed, namely the uncapacitated multiple allocation hub location problem with fixed costs (UMAHLP), is studied by Campbell (1994a), Klincewicz (1996), Ernst and Krishnamoorthy (1998a), Ebery et al. (2000), Mayer and Wagner (2002), Boland et al. (2004), Hamacher et al. (2004), Marín (2005), Cánovas et al. (2007) and Contreras et al. (2011a). Since this problem is analogous to the UMApHMP, most of the solution methods can be adapted to solve the UMApHMP.

Several Benders decomposition based approaches have been proposed to solve the uncapacitated multiple allocation hub location problems and they proved to be effective. To the best of our knowledge, Camargo et al. (2008) are the first ones to apply Benders decomposition to the uncapacitated multiple allocation hub location problem. They propose three different Benders approaches. The first one is the classical approach, which adds a single cut at each iteration, while the second is the multi-cut version in which Benders cuts are generated for each origin-destination pair. Another variant allows an error margin $\epsilon$ for the cuts added and the algorithm terminates when an $\epsilon$-optimal solution is obtained. They solve instances with up to 200 nodes and conclude that the single-cut version of the algorithm shows the best computational performance. Contreras et al. (2011a) propose a Benders decomposition algorithm to solve UMAHLP. They generate cuts for each candidate 
hub location instead of each origin-destination pair. They construct pareto-optimal cuts in order to improve the convergence of the algorithm and offer elimination tests to reduce the size of the problem. Using the proposed approaches, they succeed to solve instances with up to 500 nodes.

Benders decomposition is also used to solve other variants of the multiple allocation hub location problems. Camargo et al. (2009) study UMAHLP where the discount factor for the connections between hub nodes is defined as a piecewiselinear concave function. They devise two Benders decomposition algorithms generating cuts for each origin-destination pair in each Benders iteration. Instances with up to 50 nodes from the Civil Aeronautics Board (CAB) data set and Australian Post (AP) data set are solved within six hours of CPU time. Gelareh and Nickel (2011) work on UMAHLP for the urban transportation and liner shipping networks where the hub network is incomplete and the triangularity assumption does not hold. In order to solve this problem, they proposed a Benders decomposition algorithm such that cuts are generated for each node instead of each origin-destination pair. The algorithm is tested on the AP data set instances with up to 50 nodes and all the instances are solved within one hour.

Many variants of the hub location problem have been studied in the last decades: O'Kelly and Miller (1994), Nickel et al. (2001), Yoon and Current (2008), Calık et al. (2009) and Alumur et al. (2009) relax the assumption of a complete hub network. Labbé and Yaman (2008), Yaman (2008) and Yaman and Elloumi (2012) study problems with star hub networks. Yaman et al. (2007a) study the problem with stopovers. Contreras et al. (2010) study a tree structure and Yaman (2009) and Alumur et al. (2012b) study hierarchical hub networks. The problem of locating a given number of hub arcs with discounted costs is introduced in Campbell et al. (2005a, 2005b). Podnar et al. (2002) propose to discount the transportation cost of the flows exceeding a threshold. O'Kelly and Bryan (1998), Horner and O'Kelly (2001) and Camargo et al. (2009) model economies of scale as a function of flow. Yaman (2011) studies the $r$-allocation variant where a node can be allocated to up to $r$ hub nodes and O'Kelly et al. (2015) study the problem with fixed arc costs. An et al. (2015) consider disruptions in the hub network and incorporate reliability issues into the hub location problem. Correia et al. (2010) study the problem where the sizes of the hubs are also decided along with their locations.

Even though the classical hub location problems and their variants are well studied over the years, the literature addressing data uncertainty in the context of hub location problems is rather limited. Marianov and Serra (2003) investigate a hub location problem in an air transportation network in which hubs are assumed to behave as $M / D / c$ queues. The probability that the number of planes in the queue exceeds a certain number is bounded above. This restriction is later transformed into a capacity constraint for the hubs. The authors propose a tabu search based heuristic method and test it using the CAB data set and a randomly generated data set containing 900 instances with 30 nodes.

Yang (2009) introduces demand uncertainty into the air freight hub location and flight routes planning problem in a twostage stochastic programming setting. In the first stage, the number of hubs to be opened and the locations of these hubs are determined. The second stage deals with the flight routing decisions in response to different demand scenarios considering the hub locations determined in the first stage. Computational experiments are performed using real data from TaiwanChina air freight network. Comparison of the stochastic model with the deterministic model based on average demands shows that incorporating uncertainty into the problem leads to improvements in the total cost.

Sim et al. (2009) study stochastic $p$-hub center problem with normally distributed travel times. They use a chance constraint to guarantee the desired service level. They propose several heuristic algorithms and test them on the CAB and the AP data sets.

Contreras et al. (2011b) consider the uncapacitated multiple allocation hub location problem under demand and transportation cost uncertainty. They show that the stochastic models for this problem with uncertain demands or transportation costs dependent to a single uncertain parameter are equivalent to the deterministic problem with mean values. This is not the case for the problem with stochastic independent transportation costs. This latter problem is solved using Benders decomposition and a sample average scheme. They use the AP data set to test the efficiency and effectiveness of the proposed models and algorithms.

Alumur et al. (2012a) study both multiple and single allocation hub location problems with setup costs and point-to-point demands as sources of uncertainty. The uncertainty in the setup costs is handled by a minmax regret formulation while demand uncertainty is modeled with a stochastic programming formulation. They integrate these two cases and propose a model considering both setup cost and demand uncertainty. Computational analysis of the proposed models is performed with more than 150 instances on the CAB data.

Most recently, Shahabi and Unnikrishnan (2014) study the single and multiple allocation hub location problems with ellipsoidal demand uncertainty. They propose mixed integer conic quadratic programming formulations and a linear relaxation strategy. The proposed models are tested on the CAB data set with 25 nodes and it is concluded that more hubs are opened as the level of uncertainty increases.

Different from the studies summarized above, in this study, we adopt two polyhedral uncertainty sets from the telecommunications literature, namely hose and hybrid models, to represent the uncertainty in the demand data. We formulate the UMApHMP under hose and hybrid demand uncertainty as mixed integer linear programming problems. Motivated by successful implementations of Benders decomposition to solve hub locations problems, we propose two different exact decomposition algorithms to solve large-scale instances. Note that the solution methods proposed in this study can be easily adapted to solve the uncapacitated multiple allocation hub location problem where the number of hubs to be opened is not fixed and there is a cost associated with installing hub facilities. 


\section{Models}

In this section, we devise mathematical models for the multiple allocation $p$-hub median problem under different models of demand uncertainty. We consider the uncapacitated problem where the hub network is complete and there is no direct connection between nonhub nodes. Several formulations are developed for the deterministic UMApHMP. We use the model proposed by Hamacher et al. (2004).

We are given a set of demand points $N=\{1, \ldots, n\}$ and a set of possible hub locations $H=\{1, \ldots, h\}$. In the deterministic problem, we know the traffic demand $w_{i j}$ from node $i$ to node $j$ for all distinct pairs $i$ and $j$ (we assume that $w_{i i}=0$ for all nodes $i$ ). Let $C=\{(i, j): i, j \in N, i \neq j\}$. We denote by $d_{i j}$ the cost of transporting one unit of demand from node $i$ to node $j$. We have cost multipliers $\chi, \alpha$ and $\delta$ for collection, transfer between hubs and distribution, respectively. Hence the cost of transporting one unit of demand from node $i$ to node $j$ through hubs $k$ and $m$ is equal to $c_{i j k m}=\chi d_{i k}+\alpha d_{k m}+\delta d_{m j}$.

For completeness, we first present the model of Hamacher et al. (2004) for the deterministic problem. Let $y_{k}$ be 1 if a hub is located at location $k$ and be 0 otherwise and $x_{i j k m}$ be the fraction of flow from node $i$ to node $j$ sent through hubs $k$ and $m$ in that order. The model is as follows:

(UMA $p$ HMP deterministic)

$$
\begin{aligned}
& \min \sum_{(i, j) \in C} \sum_{k \in H} \sum_{m \in H} c_{i j k m} w_{i j} x_{i j k m} \\
& \text { s.t. } \sum_{k} y_{k}=p, \\
& \sum_{k \in H} \sum_{m \in H} x_{i j k m}=1 \quad \forall(i, j) \in C, \\
& \sum_{m \in H} x_{i j k m}+\sum_{\substack{m \in H \\
m \neq k}} x_{i j m k} \leq y_{k} \quad \forall(i, j) \in C, k \in H, \\
& y_{k} \in\{0,1\} \quad \forall k \in H, \\
& x_{i j k m} \geq 0 \quad \forall(i, j) \in C, \quad \forall k, m \in H .
\end{aligned}
$$

The objective is to minimize the total transportation cost. Constraint (2) ensures that $p$ hubs are located in the network. Constraints (3) guarantee that the demand between each origin-destination pair is fully satisfied. Constraints (4) assure that the flow can go through only installed hub facilities. Constraints (5) and (6) are the domain constraints.

We consider two demand uncertainty models, the hose model and the hybrid model. In the telecommunications community, the hose model is a popular way to model demand uncertainty. It puts limitations on the total demand associated to demand nodes, rather than estimating pairwise demand values.

The total demand adjacent at each node $i \in N$ is required to be less than or equal to a finite and non-negative upper bound $b_{i}$. The uncertainty set under hose uncertainty model is

$$
D_{\text {hose }}=\left\{w \in \mathbb{R}_{+}^{n(n-1)}: \sum_{j \in N \backslash\{i\}} w_{i j}+\sum_{j \in N \backslash\{i\}} w_{j i} \leq b_{i}, \forall i \in N\right\} \text {. }
$$

The robust multiple allocation $p$-hub median problem under hose uncertainty asks to decide on the locations of hubs and the routes for origin-destination pairs so that the worst case cost over all possible demand realizations in set $D_{\text {hose }}$ is minimized, i.e.,

$$
\min _{(x, y) \in X} \max _{w \in D_{\text {hose }}} \sum_{(i, j) \in C} \sum_{k \in H} \sum_{m \in H} c_{i j k m} w_{i j} x_{i j k m},
$$

where $X$ is the set defined by constraints (2)-(6).

As such, this problem is a nonlinear problem. Next we apply the dual transformation used to linearize minmax type robust optimization problems (see, e.g., Altın et al., 2011b; Bertsimas and Sim, 2003). For given $(x, y) \in X$, the problem

$$
\max _{w \in D_{\text {hose }}} \sum_{(i, j) \in C} \sum_{k \in H} \sum_{m \in H} c_{i j k m} w_{i j} x_{i j k m}
$$

is a linear programming problem that is feasible and bounded. Hence, its optimal value is equal to the optimal value of its dual. Using this result, robust UMApHMP with hose demand uncertainty can be modeled as the following mixed integer program:

\section{(UMA $p$ HMP Hose)}

$$
\begin{aligned}
& \min \sum_{i \in N} \lambda_{i} b_{i} \\
& \text { s.t. (2)-(6), }
\end{aligned}
$$




$$
\begin{aligned}
& \lambda_{i}+\lambda_{j} \geq \sum_{k \in H} \sum_{m \in H} c_{i j k m} x_{i j k m} \quad \forall(i, j) \in C, \\
& \lambda_{i} \geq 0 \quad \forall i \in N,
\end{aligned}
$$

where $\lambda_{i}$ is the dual variable associated with the constraint $\sum_{j \in N \backslash\{i\}} w_{i j}+\sum_{j \in N \backslash\{i\}} w_{j i} \leq b_{i}$ for $i \in N$.

The second uncertainty set we study is the hybrid set proposed by Altın et al. (2011b):

$$
D_{\text {hybrid }}=D_{\text {hose }} \cap\left\{w \in \mathbb{R}_{+}^{n(n-1)}: l_{i j} \leq w_{i j} \leq u_{i j}, \forall(i, j) \in C\right\},
$$

where $l_{i j}$ and $u_{i j}$ are lower and upper bounds for the traffic demand from node $i$ to node $j$ with $0 \leq l_{i j} \leq u_{i j}$. Note that when $l_{i j}=0$ and $u_{i j} \geq \min \left\{b_{i}, b_{j}\right\}$ for all distinct pairs $i$ and $j, D_{\text {hybrid }}=D_{\text {hose }}$. In addition, when $u_{i j}=l_{i j}$ for all $(i, j) \in C$ and $b_{i} \geq \sum_{j \in N \backslash\{i\}}\left(u_{i j}+u_{j i}\right)$ for all $i$, we have the deterministic problem.

The robust multiple allocation $p$-hub median problem under hybrid uncertainty can be modeled as follows:

\section{(UMA $p$ HMP Hybrid)}

$$
\begin{aligned}
& \min \sum_{i \in N} \lambda_{i} b_{i}+\sum_{(i, j) \in C}\left(u_{i j} \beta_{i j}-l_{i j} \mu_{i j}\right) \\
& \text { s.t. }(2)-(6), \\
& \lambda_{i}+\lambda_{j}+\beta_{i j}-\mu_{i j} \geq \sum_{k \in H} \sum_{m \in H} c_{i j k m} x_{i j k m} \quad \forall(i, j) \in C, \\
& \lambda_{i} \geq 0 \quad \forall i \in N, \\
& \beta_{i j}, \mu_{i j} \geq 0 \quad \forall(i, j) \in C,
\end{aligned}
$$

where $\beta_{i j}$ and $\mu_{i j}$ are the dual variables associated with the upper and lower bound constraints, respectively.

Both models UMApHMP Hose and UMApHMP Hybrid are compact mixed integer programming models that can be solved using a general purpose solver. However, as the number of nodes grows, the sizes of these formulations grow quickly. In the sequel, we propose decomposition algorithms to deal with these large mixed integer programs.

\section{Benders decomposition}

Benders decomposition is a row generation based exact solution method that can be applied to solve large-scale mixed integer programming problems (Benders, 1962). In this technique, the problem is reformulated using a smaller number of variables and a large number of constraints. Then this reformulation is solved using a cutting plane approach. The relaxation solved at each iteration is called as the master problem and the problem that finds a cutting plane is called as the subproblem.

Benders decomposition uses the fact that computational difficulty of a problem increases as the problem size increases and instead of solving a single large problem, solving smaller problems iteratively may be more efficient in terms of the computational effort required. With this motivation, we apply Benders decomposition to the robust UMApHMP under polyhedral demand uncertainty. In the classical Benders approach, the master problem is solved to optimality at each iteration. In our implementations, we use a branch-and-cut framework to solve the master problem in a single attempt by utilizing recent developments in off-the-shelf solvers. Benders cuts are separated each time a candidate integer solution is found in the branch-and-cut tree of the master problem. In this way, we avoid the computational burden of solving an integer problem at each iteration.

We decompose UMApHMP with polyhedral demand uncertainty in two different ways. We present our approach for only the hybrid uncertainty model since the hose model is a special case with $l_{i j}=0$ and $u_{i j} \geq \min \left\{b_{i}, b_{j}\right\}$.

\subsection{Decomposition with only location variables in the master}

Consider the formulation UMApHMP Hybrid we provided in the previous section. For given hub locations represented with vector $\hat{y}$, the problem becomes

$$
\begin{aligned}
& \text { (PS1) } \min \sum_{i \in N} \lambda_{i} b_{i}+\sum_{(i, j) \in C}\left(u_{i j} \beta_{i j}-l_{i j} \mu_{i j}\right) \\
& \text { s.t. } \lambda_{i}+\lambda_{j}+\beta_{i j}-\mu_{i j} \geq \sum_{k \in H} \sum_{m \in H} c_{i j k m} x_{i j k m} \quad \forall(i, j) \in C, \\
& \sum_{k \in H} \sum_{m \in H} x_{i j k m} \geq 1 \quad \forall(i, j) \in C,
\end{aligned}
$$




$$
\begin{aligned}
& \sum_{m \in H} x_{i j k m}+\sum_{m \in H \backslash\{k\}} x_{i j m k} \leq \hat{y}_{k} \quad \forall(i, j) \in C, k \in H, \\
& \lambda_{i} \geq 0 \quad \forall i \in N, \\
& \beta_{i j}, \mu_{i j} \geq 0 \quad \forall(i, j) \in C, \\
& x_{i j k m} \geq 0 \quad \forall(i, j) \in C, \forall k, m \in H .
\end{aligned}
$$

Note here that we modified constraints (18) as inequalities since the above model has an optimal solution where these inequalities are tight. Problem PS1 is a linear programming problem. It is feasible and bounded when $\sum_{k \in H} \hat{y}_{k} \geq 1, u_{i j} \geq$ $l_{i j} \geq 0$ for all $(i, j) \in C$ and $b_{i} \geq \sum_{j \in N \backslash\{i\}}\left(l_{i j}+l_{j i}\right)$ for all $i \in N$. We associate dual variables $\omega_{i j}$, $\rho_{i j}$ and $v_{i j k}$ to constraints (17)-(19), respectively. Then the dual subproblem is

$$
\begin{aligned}
& \text { (DS1) } \max \sum_{(i, j) \in C} \rho_{i j}-\sum_{(i, j) \in C} \sum_{k \in H} \hat{y}_{k} v_{i j k} \\
& \text { s.t. } \sum_{j \in N \backslash\{i\}} \omega_{i j}+\sum_{j \in N \backslash\{i\}} \omega_{j i} \leq b_{i} \quad \forall i \in N, \\
& l_{i j} \leq \omega_{i j} \leq u_{i j} \quad \forall(i, j) \in C, \\
& \rho_{i j}-v_{i j k}-v_{i j m} \leq c_{i j k m} \omega_{i j} \quad \forall(i, j) \in C, \quad \forall k, m \in H: k \neq m, \\
& \rho_{i j}-v_{i j k} \leq c_{i j k k} \omega_{i j} \quad \forall(i, j) \in C, k \in H, \\
& \rho_{i j} \geq 0 \quad \forall(i, j) \in C, \\
& v_{i j k} \geq 0 \quad \forall(i, j) \in C, \quad \forall k \in H,
\end{aligned}
$$

and is also feasible and bounded by strong duality. Hence, the robust UMApHMP under hybrid demand uncertainty can be modeled as the master problem

(MP1) $\min q$

$$
\begin{aligned}
& \text { s.t. } q \geq \sum_{(i, j) \in C} \rho_{i j}^{t}-\sum_{(i, j) \in C} \sum_{k \in H} y_{k} v_{i j k}^{t} \quad \forall t=1, \ldots, T, \\
& \sum_{k} y_{k}=p, \\
& y_{k} \in\{0,1\} \quad \forall k \in H,
\end{aligned}
$$

where $\left(\rho^{t}, v^{t}, \omega^{t}\right)$ is the tth extreme point of the set defined by (23)-(28). We solve this master problem iteratively using constraints (30) as cutting planes. For a given $(\hat{q}, \hat{y})$, we check whether there exists an inequality $(30)$ that is violated by solving the dual subproblem. Now, we investigate how the dual problem can be solved efficiently.

First, in order to eliminate the dependencies between the constraints, we let $\bar{\rho}_{i j}=\frac{\rho_{i j}}{\omega_{i j}}$ and $\bar{v}_{i j k}=\frac{v_{i j k}}{\omega_{i j}}$. Then the dual subproblem becomes

$$
\max \sum_{(i, j) \in C} \omega_{i j}\left(\bar{\rho}_{i j}-\sum_{k \in H} \hat{y}_{k} \bar{v}_{i j k}\right)
$$

s.t. (23) and (24),

$$
\begin{aligned}
& \bar{\rho}_{i j}-\bar{v}_{i j k}-\bar{v}_{i j m} \leq c_{i j k m} \quad \forall(i, j) \in C, \forall k, m \in H: k \neq m, \\
& \bar{\rho}_{i j}-\bar{v}_{i j k} \leq c_{i j k k} \quad \forall(i, j) \in C, \quad \forall k \in H, \\
& \bar{\rho}_{i j} \geq 0 \quad \forall(i, j) \in C, \\
& \bar{v}_{i j k} \geq 0 \forall(i, j) \in C, \quad \forall k \in H,
\end{aligned}
$$


which is equivalent to

$$
\max _{\omega \in D_{\text {hybrid }}}\left(\max _{(\bar{\rho}, \bar{v}):(33)-(36)} \sum_{(i, j) \in C} \omega_{i j}\left(\bar{\rho}_{i j}-\sum_{k \in H} \hat{y}_{k} \bar{\nu}_{i j k}\right)\right) \text {. }
$$

Now the inner problem decomposes into $n(n-1)$ problems:

$$
\max _{\omega \in D_{\text {hybrid }}} \sum_{(i, j) \in C} \omega_{i j} \theta_{i j},
$$

where for $(i, j) \in C$,

$$
\begin{aligned}
& \theta_{i j}=\max \bar{\rho}_{i j}-\sum_{k \in H} \hat{y}_{k} \bar{v}_{i j k} \\
& \text { s.t. } \bar{\rho}_{i j}-\bar{v}_{i j k}-\bar{v}_{i j m} \leq c_{i j k m} \quad \forall k, m \in H: k \neq m \text {, } \\
& \bar{\rho}_{i j}-\bar{v}_{i j k} \leq c_{i j k k} \quad \forall k \in H, \\
& \bar{\rho}_{i j} \geq 0 \text {, } \\
& \bar{v}_{i j k} \geq 0 \quad \forall k \in H,
\end{aligned}
$$

which is the dual of

$$
\begin{aligned}
\theta_{i j}=\min & \sum_{k \in H} \sum_{m \in H} c_{i j k m} x_{i j k m} \\
\text { s.t. } & \sum_{k \in H} \sum_{m \in H} x_{i j k m} \geq 1, \\
& \sum_{m \in H} x_{i j k m}+\sum_{m \in H \backslash\{k\}} x_{i j m k} \leq \hat{y}_{k} \quad \forall k \in H, \\
& x_{i j k m} \geq 0 \quad \forall k, m \in H .
\end{aligned}
$$

This problem can be solved by inspection and an optimal dual solution can be constructed using complementary slackness conditions as explained by Contreras et al. (2011a). We note here that the dual problem computes the worst case cost for a given choice of hub locations and it uses the fact that each commodity is routed on a shortest path from its origin to its destination, independently of the demand realizations. Hence, we first compute the length of a shortest path for each origindestination pair and then solve a linear problem to find the demand realization for which the routing cost is maximum.

Besides, different from the deterministic case, the cut (30) cannot be disaggregated into cuts for nodes or for node pairs since the problem DS1 does not decompose.

\subsection{Decomposition by projecting out the routing variables}

When we fix $(y, \lambda, \beta, \mu)=(\hat{y}, \hat{\lambda}, \hat{\beta}, \hat{\mu})$ in formulation UMApHMP Hybrid, we obtain the following problem

$$
\begin{aligned}
& \max 0 x \\
& \text { s.t. } \sum_{k \in H} \sum_{m \in H} c_{i j k m} x_{i j k m} \leq \hat{\lambda}_{i}+\hat{\lambda}_{j}+\hat{\beta}_{i j}-\hat{\mu}_{i j} \quad \forall(i, j) \in C, \\
& \sum_{k \in H} \sum_{m \in H} x_{i j k m} \geq 1 \quad \forall(i, j) \in C, \\
& \sum_{m \in H} x_{i j k m}+\sum_{m \in H \backslash\{i\}} x_{i j m k} \leq \hat{y}_{k} \quad \forall(i, j) \in C, k \in H, \\
& x_{i j k m} \geq 0 \forall(i, j) \in C, \forall k, m \in H,
\end{aligned}
$$

which is a feasibility problem. For this problem to be feasible, we need its dual to be bounded. In other words, by Farkas' lemma, we need

$$
\sum_{(i, j) \in C}\left(\hat{\lambda}_{i}+\hat{\lambda}_{j}+\hat{\beta}_{i j}-\hat{\mu}_{i j}\right) \gamma_{i j}-\sum_{(i, j) \in C} \rho_{i j}+\sum_{(i, j) \in C} \sum_{k \in H} v_{i j k} \hat{y}_{k} \geq 0
$$

for all $(\gamma, \rho, v)$ that satisfy

$$
\begin{array}{lr}
\gamma_{i j} c_{i j k m}-\rho_{i j}+v_{i j k}+v_{i j m} \geq 0 & \forall(i, j) \in C, \quad \forall k, m \in H: k \neq m, \\
\gamma_{i j} c_{i j k k}-\rho_{i j}+v_{i j k} \geq 0 & \forall(i, j) \in C, \forall k \in H, \\
\gamma_{i j} \geq 0, \rho_{i j} \geq 0 & \forall(i, j) \in C, \\
v_{i j k} \geq 0 & \forall(i, j) \in C, \forall k, m \in H .
\end{array}
$$




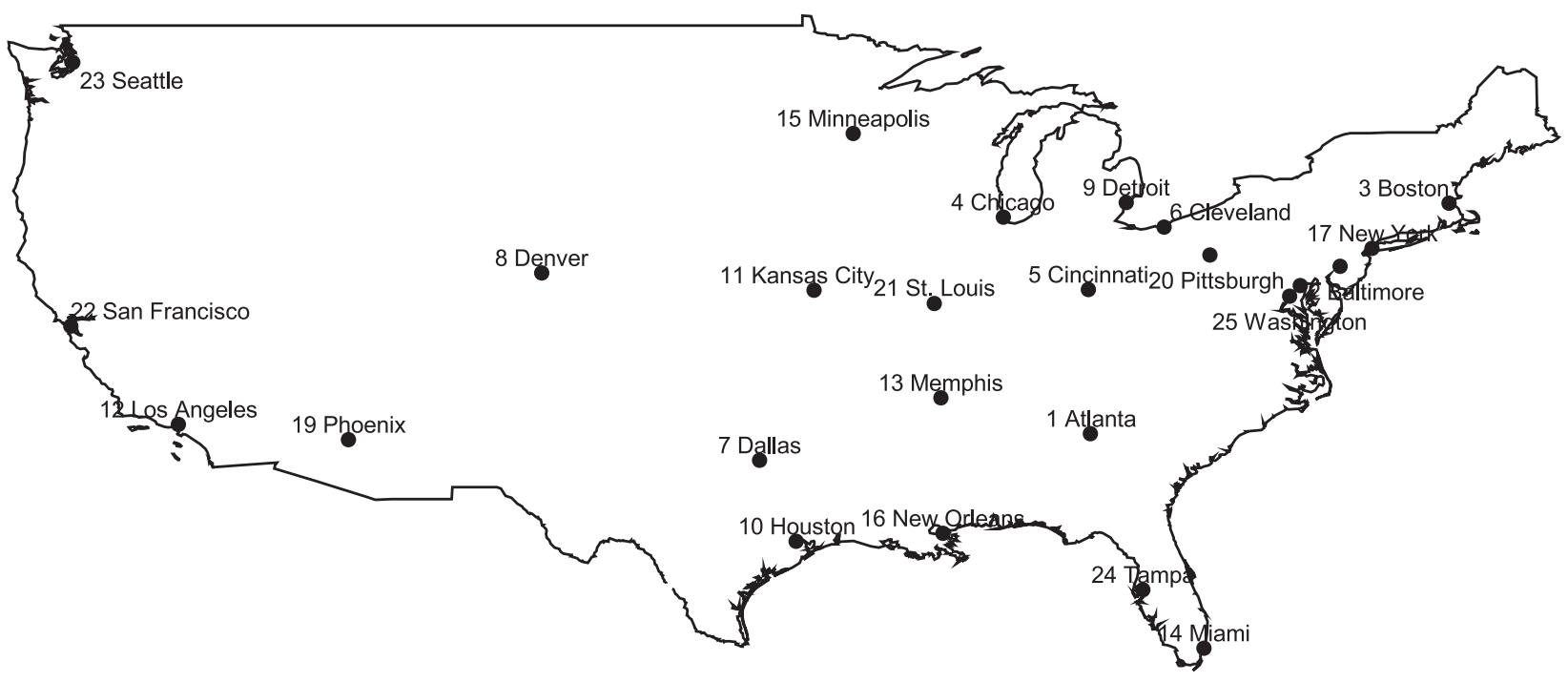

Fig. 1. Locations of demand nodes for $C A B$ data set.

First note that this system decomposes for each pair $(i, j)$. In addition, since the vector can be scaled, we take $\gamma_{i j}$ to be 0 or 1 without loss of generality. When $\gamma_{i j}=0$, we need $\sum_{k \in H} v_{i j k} \hat{y}_{k} \geq \rho_{i j}$ for all $\left(\rho_{i j}, v_{i j}\right)$ such that

$$
\begin{array}{lr}
v_{i j k}+v_{i j m} \geq \rho_{i j} & \forall k, m \in H: k \neq m, \\
v_{i j k} \geq \rho_{i j} & \forall k \in H, \\
\rho_{i j} \geq 0, & \\
v_{i j k} \geq 0 & \forall k, m \in H .
\end{array}
$$

This is always satisfied when $\sum_{k \in H} \hat{y}_{k} \geq 1$. Hence, the only interesting case is $\gamma_{i j}=1$. Consequently, we can conclude that the feasibility problem has a solution if for all $(i, j) \in C$ we have

$$
\hat{\lambda}_{i}+\hat{\lambda}_{j}+\hat{\beta}_{i j}-\hat{\mu}_{i j} \geq \rho_{i j}-\sum_{k \in H} v_{i j k} \hat{y}_{k}
$$

for all $\left(\rho_{i j}, v_{i j}\right)$ such that

$$
\begin{aligned}
& c_{i j k m}+v_{i j k}+v_{i j m} \geq \rho_{i j} \quad \forall k, m \in H: k \neq m, \\
& c_{i j k k}+v_{i j k} \geq \rho_{i j} \quad \forall k \in H, \\
& \rho_{i j} \geq 0,
\end{aligned}
$$

$$
v_{i j k} \geq 0 \quad \forall k, m \in H .
$$

Let $M_{i j}=\left\{\left(\rho_{i j}, v_{i j}\right) \in \mathbb{R}_{+} \times \mathbb{R}_{+}^{h}:(42)-(45)\right\}$ for $(i, j) \in C$. After projecting out the $x$ variables, the model becomes

$$
\begin{aligned}
& \text { (MP2) } \min \sum_{i \in N} \lambda_{i} b_{i}+\sum_{(i, j) \in C}\left(u_{i j} \beta_{i j}-l_{i j} \mu_{i j}\right) \\
& \text { s.t. } \quad \lambda_{i}+\lambda_{j}+\beta_{i j}-\mu_{i j} \geq \rho_{i j}^{t}-\sum_{k \in H} y_{k} v_{i j k}^{t} \quad \forall(i, j) \in C, \forall t=1, \ldots, T_{i j} \text {, } \\
& \sum_{k} y_{k}=p \\
& \lambda_{i} \geq 0 \\
& \forall i \in N \text {, } \\
& \beta_{i j}, \mu_{i j} \geq 0 \\
& y_{k} \in\{0,1\} \\
& \forall(i, j) \in C \text {, } \\
& \forall k \in H \text {, }
\end{aligned}
$$




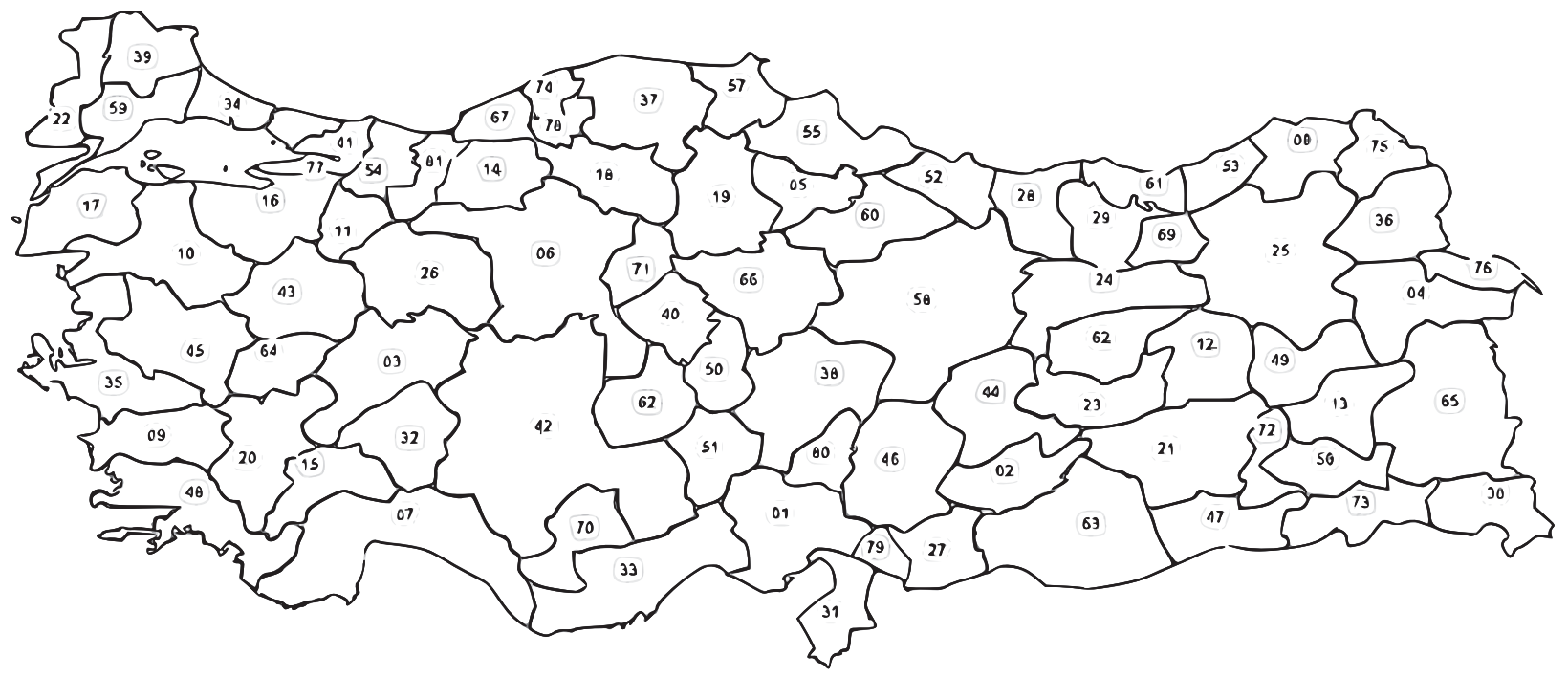

Fig. 2. Locations of demand nodes for TR data set.

Table 1

Results for the CAB data set (total transportation cost / hub locations).

\begin{tabular}{|c|c|c|c|c|c|c|c|c|c|}
\hline $\mathrm{p}$ & $\alpha$ & Deterministic & $\begin{array}{l}\text { Hybrid } \\
(\psi=0.2)\end{array}$ & $\begin{array}{l}\text { Hybrid } \\
(\psi=0.4)\end{array}$ & $\begin{array}{l}\text { Hybrid } \\
(\psi=0.6)\end{array}$ & $\begin{array}{l}\text { Hybrid } \\
(\psi=0.8)\end{array}$ & $\begin{array}{l}\text { Hybrid } \\
(\psi=1)\end{array}$ & $\begin{array}{l}\text { Hybrid } \\
(\psi=2)\end{array}$ & Hose \\
\hline \multirow[t]{2}{*}{2} & 0.2 & 996.02 & 1007.72 & 1019.41 & 1031.10 & 1042.80 & 1054.49 & 1054.99 & 1054.99 \\
\hline & & 12,20 & 12,20 & 12,20 & 12,20 & 12,20 & 12,20 & 12,20 & 12,20 \\
\hline \multirow[t]{2}{*}{2} & 0.4 & 1072.49 & 1095.61 & 1118.73 & 1141.84 & 1164.96 & 1188.08 & 1190.79 & 1190.79 \\
\hline & & 12,20 & 12,20 & 12,20 & 12,20 & 12,20 & 12,20 & 12,20 & 12,20 \\
\hline \multirow[t]{2}{*}{2} & 0.6 & 1137.08 & 1172.03 & 1206.98 & 1241.87 & 1269.64 & 1297.42 & 1319.78 & 1319.78 \\
\hline & & 12,20 & 12,20 & 12,20 & 8,20 & 8,20 & 8,20 & 12,20 & 12,20 \\
\hline \multirow[t]{2}{*}{2} & 0.8 & 1180.02 & 1222.71 & 1256.55 & 1290.39 & 1318.08 & 1342.32 & 1417.49 & 1418.84 \\
\hline & & 12,20 & 8,20 & 8,20 & 8,20 & 11,20 & 11,20 & 8,20 & 5,12 \\
\hline \multirow[t]{2}{*}{3} & 0.2 & 752.91 & 770.59 & 788.02 & 805.36 & 822.70 & 839.44 & 845.12 & 845.26 \\
\hline & & $12,17,21$ & $12,17,21$ & $4,12,17$ & $4,12,17$ & $4,12,17$ & $5,12,17$ & $5,12,17$ & $5,12,17$ \\
\hline \multirow[t]{2}{*}{3} & 0.4 & 859.64 & 893.41 & 927.19 & 960.96 & 994.66 & 1024.40 & 1036.58 & 1037.64 \\
\hline & & $4,12,17$ & $4,12,17$ & $4,12,17$ & $4,12,17$ & $4,12,18$ & $5,12,17$ & $5,12,17$ & $5,12,17$ \\
\hline \multirow[t]{2}{*}{3} & 0.6 & 949.23 & 996.94 & 1044.22 & 1091.50 & 1136.48 & 1180.64 & 1209.00 & 1213.09 \\
\hline & & $4,12,17$ & $4,12,18$ & $4,12,18$ & $4,12,18$ & $2,12,21$ & $2,12,21$ & $5,12,17$ & $5,12,17$ \\
\hline \multirow[t]{2}{*}{3} & 0.8 & 1020.04 & 1079.13 & 1136.03 & 1190.64 & 1244.66 & 1293.22 & 1359.06 & 1367.93 \\
\hline & & $4,12,17$ & $12,18,21$ & $2,12,21$ & $2,12,21$ & $12,21,25$ & $12,20,21$ & $5,8,17$ & $5,12,17$ \\
\hline \multirow[t]{2}{*}{4} & 0.2 & 618.48 & 635.69 & 652.91 & 670.12 & 687.33 & 704.54 & 722.29 & 726.44 \\
\hline & & $4,12,17,24$ & $4,12,17,24$ & $4,12,17,24$ & $4,12,17,24$ & $4,12,17,24$ & $4,12,17,24$ & $4,12,17,24$ & $4,12,14,17$ \\
\hline \multirow[t]{2}{*}{4} & 0.4 & 754.49 & 788.62 & 821.96 & 854.22 & 886.47 & 918.73 & 954.92 & 967.16 \\
\hline & & $4,12,17,24$ & $4,12,17,24$ & $1,4,12,17$ & $1,4,12,17$ & $1,4,12,17$ & $1,4,12,17$ & $1,4,12,17$ & $5,12,14,17$ \\
\hline \multirow[t]{2}{*}{4} & 0.6 & 866.45 & 914.26 & 962.07 & 1009.88 & 1057.70 & 1105.51 & 1156.82 & 1170.07 \\
\hline & & $1,4,12,17$ & $1,4,12,17$ & $1,4,12,17$ & $1,4,12,17$ & $1,4,12,17$ & $1,4,12,17$ & $1,4,12,17$ & $5,12,17,24$ \\
\hline \multirow[t]{2}{*}{4} & 0.8 & 951.76 & 1013.03 & 1074.31 & 1135.59 & 1196.86 & 1251.39 & 1326.78 & 1343.21 \\
\hline & & $1,4,12,17$ & $1,4,12,17$ & $1,4,12,17$ & $1,4,12,17$ & $1,4,12,17$ & $1,4,8,17$ & $4,5,12,17$ & $5,12,17,22$ \\
\hline \multirow[t]{2}{*}{5} & 0.2 & 530.00 & 547.75 & 565.50 & 583.25 & 601.00 & 618.74 & 639.79 & 646.72 \\
\hline & & $4,7,12,14,17$ & $4,7,12,14,17$ & $4,7,12,14,17$ & $4,7,12,14,17$ & $4,7,12,14,17$ & $4,7,12,14,17$ & $4,7,12,14,17$ & $4,7,12,14,17$ \\
\hline \multirow[t]{2}{*}{5} & 0.4 & 676.34 & 711.42 & 746.51 & 781.60 & 816.68 & 851.77 & 899.59 & 914.10 \\
\hline & & $4,7,12,14,17$ & $4,7,12,14,17$ & $4,7,12,14,17$ & $4,7,12,14,17$ & $4,7,12,14,17$ & $4,7,12,14,17$ & $4,12,13,14,17$ & 1,4,12,17,20 \\
\hline \multirow[t]{2}{*}{5} & 0.6 & 804.70 & 855.24 & 905.78 & 956.32 & 1005.79 & 1055.19 & 1112.80 & 1129.91 \\
\hline & & $4,7,12,14,17$ & $4,7,12,14,17$ & $4,7,12,14,17$ & $4,7,12,14,17$ & $4,7,12,14,18$ & $4,7,12,14,18$ & $1,4,12,17,20$ & $5,8,12,17,24$ \\
\hline \multirow[t]{2}{*}{5} & 0.8 & 910.35 & 974.35 & 1037.38 & 1098.67 & 1158.20 & 1215.17 & 1298.23 & 1322.23 \\
\hline & & $4,7,12,17,24$ & $4,7,12,17,24$ & $1,4,7,12,17$ & $4,7,12,17,25$ & $4,7,12,17,25$ & $4,8,13,17,20$ & $1,4,12,17,20$ & $5,12,14,17,22$ \\
\hline
\end{tabular}

where $\left(\rho_{i j}^{t}, v_{i j}^{t}\right)$ is the th extreme point of $M_{i j}$, which has $T_{i j}$ extreme points. Hence the dual subproblem for each $(i, j) \in C$ can be stated as

$$
\max _{\left(\rho_{i j}, v_{i j}\right) \in M_{i j}}\left(\rho_{i j}-\sum_{k \in H} y_{k} v_{i j k}\right),
$$


Table 2

Cost analysis for the $\mathrm{CAB}$ data set.

\begin{tabular}{|c|c|c|c|c|c|c|c|c|c|}
\hline \multirow[b]{2}{*}{$\mathrm{p}$} & \multirow[b]{2}{*}{$\alpha$} & \multirow[b]{2}{*}{ Deterministic } & \multicolumn{7}{|c|}{ Cost and Percentage deviation from the optimal value } \\
\hline & & & $\begin{array}{l}\text { Hybrid } \\
(\psi=0.2)\end{array}$ & $\begin{array}{l}\text { Hybrid } \\
(\psi=0.4)\end{array}$ & $\begin{array}{l}\text { Hybrid } \\
(\psi=0.6)\end{array}$ & $\begin{array}{l}\text { Hybrid } \\
(\psi=0.8)\end{array}$ & $\begin{array}{l}\text { Hybrid } \\
(\psi=1)\end{array}$ & $\begin{array}{l}\text { Hybrid } \\
(\psi=2)\end{array}$ & Hose \\
\hline \multirow[t]{2}{*}{2} & 0.2 & 12,20 & 1007.72 & 1019.41 & 1031.10 & 1042.80 & 1054.49 & 1054.99 & 1054.99 \\
\hline & & & 0.00 & 0.00 & 0.00 & 0.00 & 0.00 & 0.00 & 0.00 \\
\hline \multirow[t]{2}{*}{2} & 0.4 & 12,20 & 1095.61 & 1118.73 & 1141.84 & 1164.96 & 1188.08 & 1190.79 & 1190.79 \\
\hline & & & 0.00 & 0.00 & 0.00 & 0.00 & 0.00 & 0.00 & 0.00 \\
\hline \multirow[t]{2}{*}{2} & 0.6 & 12,20 & 1172.03 & 1206.98 & 1241.93 & 1276.88 & 1311.83 & 1319.78 & 1319.78 \\
\hline & & & 0.00 & 0.00 & 0.01 & 0.57 & 1.11 & 0.00 & 0.00 \\
\hline \multirow[t]{2}{*}{2} & 0.8 & 12,20 & 1223.51 & 1266.99 & 1310.48 & 1353.97 & 1397.45 & 1429.48 & 1430.32 \\
\hline & & & 0.07 & 0.83 & 1.56 & 2.72 & 4.11 & 0.85 & 0.81 \\
\hline \multirow[t]{2}{*}{3} & 0.2 & $12,17,21$ & 770.59 & 788.27 & 805.94 & 823.62 & 841.30 & 859.58 & 863.10 \\
\hline & & & 0.00 & 0.03 & 0.07 & 0.11 & 0.22 & 1.71 & 2.11 \\
\hline \multirow[t]{2}{*}{3} & 0.4 & $4,12,17$ & 893.41 & 927.19 & 960.96 & 994.74 & 1028.51 & 1055.69 & 1060.65 \\
\hline & & & 0.00 & 0.00 & 0.00 & 0.01 & 0.40 & 1.84 & 2.22 \\
\hline \multirow[t]{2}{*}{3} & 0.6 & $4,12,17$ & 997.32 & 1045.41 & 1093.50 & 1141.60 & 1189.69 & 1239.84 & 1250.90 \\
\hline & & & 0.04 & 0.11 & 0.18 & 0.45 & 0.77 & 2.55 & 3.12 \\
\hline \multirow[t]{2}{*}{3} & 0.8 & $4,12,17$ & 1080.04 & 1140.04 & 1200.04 & 1260.04 & 1320.05 & 1396.40 & 1414.78 \\
\hline & & & 0.08 & 0.35 & 0.79 & 1.24 & 2.07 & 2.75 & 3.43 \\
\hline \multirow[t]{2}{*}{4} & 0.2 & $4,12,17,24$ & 635.69 & 652.91 & 670.12 & 687.33 & 704.54 & 722.29 & 730.25 \\
\hline & & & 0.00 & 0.00 & 0.00 & 0.00 & 0.00 & 0.00 & 0.52 \\
\hline \multirow[t]{2}{*}{4} & 0.4 & $4,12,17,24$ & 788.62 & 822.75 & 856.88 & 891.00 & 925.13 & 961.00 & 972.51 \\
\hline & & & 0.00 & 0.10 & 0.31 & 0.51 & 0.70 & 0.64 & 0.55 \\
\hline \multirow[t]{2}{*}{4} & 0.6 & $1,4,12,17$ & 914.26 & 962.07 & 1009.88 & 1057.70 & 1105.51 & 1156.82 & 1187.47 \\
\hline & & & 0.00 & 0.00 & 0.00 & 0.00 & 0.00 & 0.00 & 1.49 \\
\hline \multirow[t]{2}{*}{4} & 0.8 & $1,4,12,17$ & 1013.03 & 1074.31 & 1135.59 & 1196.86 & 1258.14 & 1327.55 & 1372.05 \\
\hline & & & 0.00 & 0.00 & 0.00 & 0.00 & 0.54 & 0.06 & 2.15 \\
\hline \multirow[t]{2}{*}{5} & 0.2 & $4,7,12,14,17$ & 547.75 & 565.50 & 583.25 & 601.00 & 618.75 & 639.79 & 646.72 \\
\hline & & & 0.00 & 0.00 & 0.00 & 0.00 & 0.00 & 0.00 & 0.00 \\
\hline \multirow[t]{2}{*}{5} & 0.4 & $4,7,12,14,17$ & 711.42 & 746.51 & 781.60 & 816.68 & 851.77 & 900.93 & 915.26 \\
\hline & & & 0.00 & 0.00 & 0.00 & 0.00 & 0.00 & 0.15 & 0.13 \\
\hline \multirow[t]{2}{*}{5} & 0.6 & $4,7,12,14,17$ & 855.24 & 905.78 & 956.32 & 1006.86 & 1057.40 & 1135.80 & 1160.08 \\
\hline & & & 0.00 & 0.00 & 0.00 & 0.11 & 0.21 & 2.07 & 2.67 \\
\hline \multirow[t]{2}{*}{5} & 0.8 & $4,7,12,17,24$ & 974.35 & 1038.35 & 1102.35 & 1166.35 & 1230.35 & 1324.49 & 1367.82 \\
\hline & & & 0.00 & 0.09 & 0.34 & 0.70 & 1.25 & 2.02 & 3.45 \\
\hline
\end{tabular}

which is the dual of a shortest path problem from $i$ to $j$ for each $(i, j) \in C$. Again the dual variables $\rho$ and $v$ can be obtained using the algorithm provided in Contreras et al. (2011a).

Observe that keeping the dual variables $\lambda_{i}$ 's in the master problem enables us to disaggregate the cuts (30) into multiple cuts, one for each node pair.

\section{Computational analysis}

For computational analysis, we used the Civil Aeronautics Board (CAB) data set with 25 nodes, the Turkish network (TR) data set with 81 nodes and the Australian Post (AP) data set with up to 200 nodes. All data sets are well-known and commonly used in the hub location literature (accessible from OR-Library (2015)). The CAB data set (Fig. 1) was introduced by O'Kelly (1987) and is based on airline passenger interactions between 25 US cities in 1970. In this data set, the cost and demand values are symmetric and flow from one node to itself is not allowed. The unit collection and distribution cost factors are taken as $\chi=\delta=1$ while the unit transfer cost factor $\alpha$ is allowed to be $0.2,0.4,0.6,0.8$ so that $c_{i j k m}=$ $d_{i k}+\alpha d_{k m}+d_{m j}$.

We also consider the TR data set (Fig. 2) containing data for 81 cities of Turkey for cargo delivery. The unit collection, distribution and transfer cost factors are taken as in the CAB data set. Different from the CAB data, the pairwise demand values are not symmetric in the TR data set. We use the original distance values and, for the ease of representation, scale the demand values by dividing with 1000 .

Although the CAB and the TR data sets are small-to-medium size, the AP data set is available for larger instances. The AP data set is initially introduced by Ernst and Krishnamoorthy (1996) and it consists of postal delivery data for 200 postcode districts in Australia. The unit collection, transfer and distribution cost factors are taken as $\chi=3, \alpha=0.75$ and $\delta=2$. In the AP data set, demand and flow values are not symmetric. For the uniformity of computation, we do not allow flow from a node to itself even though the AP data set contains such demand values.

In order to set the problem parameters, we use the nominal demand values of the deterministic problem instances. To be able to compare our results with the available benchmark instances, we generate our traffic bounds as $b_{i}=\sum_{j \in N \backslash\{i\}}\left(w_{i j}+\right.$ $\left.w_{j i}\right)$ for all $i \in N$. For the hybrid model, we let $l_{i j}=\max \left\{0,(1-\psi) w_{i j}\right\}$ and $u_{i j}=(1+\psi) w_{i j}$ for all distinct pairs $i$ and $j$, with $\psi \in\{0.2,0.4,0.6,0.8,1,2\}$. All demand nodes are taken as candidate locations for hubs, i.e., $H=N$. 
Table 3

Results for the TR data set (total transportation cost/hub locations).

\begin{tabular}{|c|c|c|c|c|c|c|c|c|c|}
\hline $\mathrm{p}$ & $\alpha$ & Deterministic & $\begin{array}{l}\text { Hybrid } \\
(\psi=0.2)\end{array}$ & $\begin{array}{l}\text { Hybrid } \\
(\psi=0.4)\end{array}$ & $\begin{array}{l}\text { Hybrid } \\
(\psi=0.6)\end{array}$ & $\begin{array}{l}\text { Hybrid } \\
(\psi=0.8)\end{array}$ & $\begin{array}{l}\text { Hybrid } \\
(\psi=1)\end{array}$ & $\begin{array}{l}\text { Hybrid } \\
(\psi=2)\end{array}$ & Hose \\
\hline \multirow[t]{2}{*}{2} & 0.2 & 781669.72 & 786824.72 & 797134.72 & 802289.71 & 812599.71 & 822909.71 & 823485.27 & 826877.58 \\
\hline & & 44,54 & 38,41 & 38,41 & 38,41 & 38,41 & 38,41 & 38,41 & 38,41 \\
\hline \multirow[t]{2}{*}{2} & 0.4 & 820586.50 & 840112.66 & 859638.82 & 879164.99 & 892040.38 & 902575.19 & 902575.19 & 902575.19 \\
\hline & & 38,41 & 38,41 & 38,41 & 38,41 & 6,44 & 6,44 & 6,44 & 6,44 \\
\hline \multirow[t]{2}{*}{2} & 0.6 & 857219.51 & 883983.61 & 910717.95 & 926290.29 & 940622.96 & 954955.62 & 954955.62 & 954955.62 \\
\hline & & 38,41 & 38,41 & 38,54 & 6,46 & 6,46 & 6,46 & 6,46 & 6,46 \\
\hline \multirow[t]{2}{*}{2} & 0.8 & 878672.80 & 909256.41 & 938955.05 & 959486.50 & 978472.84 & 996333.67 & 996504.70 & 996504.70 \\
\hline & & 38,41 & 38,54 & 38,54 & 6,44 & 6,44 & 6,34 & 6,34 & 6,34 \\
\hline \multirow[t]{2}{*}{3} & 0.2 & 660218.05 & 669320.24 & 678208.41 & 687096.58 & 695984.75 & 704872.91 & 704872.91 & 704872.91 \\
\hline & & $12,41,68$ & $6,41,44$ & $6,41,44$ & $6,41,44$ & $6,41,44$ & $6,41,44$ & $6,41,44$ & $6,41,44$ \\
\hline \multirow[t]{2}{*}{3} & 0.4 & 726196.77 & 743571.26 & 760945.74 & 778320.22 & 795694.70 & 812263.87 & 812263.87 & 812263.87 \\
\hline & & $6,41,44$ & $6,41,44$ & $6,41,44$ & $6,41,44$ & $6,41,44$ & $6,34,44$ & $6,34,44$ & $6,34,44$ \\
\hline \multirow[t]{2}{*}{3} & 0.6 & 778077.05 & 802850.50 & 827328.13 & 851179.46 & 874652.79 & 896670.92 & 896670.92 & 896670.92 \\
\hline & & $6,41,44$ & $6,41,44$ & $6,41,46$ & $6,41,46$ & $6,34,46$ & $6,34,46$ & $6,34,46$ & $6,34,46$ \\
\hline \multirow[t]{2}{*}{3} & 0.8 & 845601.96 & 861246.30 & 892534.96 & 908179.30 & 939110.71 & 963781.26 & 968747.12 & 968747.41 \\
\hline & & $6,41,44$ & $6,41,44$ & $6,41,44$ & $6,41,44$ & $6,34,44$ & $1,3,6$ & $6,34,44$ & $6,34,44$ \\
\hline \multirow[t]{2}{*}{4} & 0.2 & 570217.55 & 580050.10 & 589882.64 & 598397.47 & 606822.73 & 615247.99 & 618170.78 & 619704.92 \\
\hline & & $6,34,44,45$ & $6,34,44,45$ & $6,34,44,45$ & $27,34,64,71$ & $27,34,64,71$ & $27,34,64,71$ & $27,34,64,71$ & $6,34,35,44$ \\
\hline \multirow[t]{2}{*}{4} & 0.4 & 657662.12 & 676223.28 & 694784.44 & 713345.61 & 731857.44 & 749377.80 & 751689.75 & 751736.11 \\
\hline & & $6,34,44,45$ & $6,34,44,45$ & $6,34,44,45$ & $6,34,44,45$ & $6,34,35,44$ & $3,34,71,80$ & $6,34,35,44$ & $6,34,35,44$ \\
\hline \multirow[t]{2}{*}{4} & 0.6 & 729447.41 & 755449.94 & 780891.70 & 804676.28 & 828223.76 & 849488.45 & 856918.94 & 856956.89 \\
\hline & & $6,34,44,45$ & $6,34,45,46$ & $6,34,45,46$ & $3,6,34,46$ & $3,6,34,46$ & $1,3,6,34$ & $1,6,23,34$ & $1,6,23,34$ \\
\hline \multirow[t]{2}{*}{4} & 0.8 & 777778.51 & 811709.80 & 843479.75 & 875182.54 & 906333.49 & 933544.51 & 947749.84 & 950994.70 \\
\hline & & $1,3,41,58$ & $1,6,23,41$ & $3,6,34,44$ & $3,6,34,44$ & $3,6,34,46$ & $1,3,6,34$ & $3,6,34,38$ & $1,6,34,44$ \\
\hline \multirow[t]{2}{*}{5} & 0.2 & 492494.33 & 501839.91 & 511185.49 & 520391.93 & 529385.67 & 538379.41 & 540666.63 & 541609.30 \\
\hline & & $6,12,34,45,80$ & $6,12,34,45,80$ & $6,12,34,45,80$ & $1,6,12,34,35$ & $1,6,12,34,35$ & $1,6,12,34,35$ & $6,12,34,35,80$ & $6,12,34,35,80$ \\
\hline \multirow[t]{2}{*}{5} & 0.4 & 595161.93 & 613491.23 & 631820.52 & 650149.82 & 668479.11 & 685959.90 & 691650.49 & 693039.20 \\
\hline & & $1,6,12,34,45$ & $1,6,12,34,45$ & $1,6,12,34,45$ & $1,6,12,34,45$ & $1,6,12,34,45$ & $1,6,12,34,64$ & $1,6,23,34,35$ & $1,6,23,34,35$ \\
\hline \multirow[t]{2}{*}{5} & 0.6 & 678419.46 & 705452.52 & 732038.97 & 757265.98 & 782009.47 & 806752.95 & 816929.99 & 821577.20 \\
\hline & & $1,6,23,34,45$ & $1,6,23,34,45$ & $1,6,23,34,64$ & $1,3,6,23,34$ & $1,3,6,23,34$ & $1,3,6,23,34$ & $1,3,6,23,34$ & $1,3,6,23,34$ \\
\hline \multirow[t]{2}{*}{5} & 0.8 & 744056.84 & 779668.60 & 812942.30 & 846138.12 & 879333.95 & 912157.71 & 928125.96 & 935014.05 \\
\hline & & $1,6,23,41,45$ & $1,3,6,23,41$ & $1,3,6,23,34$ & $1,3,6,23,34$ & $1,3,6,23,34$ & $1,3,6,34,44$ & $1,3,6,34,44$ & $1,3,6,23,34$ \\
\hline
\end{tabular}

The experiments are done on a 64-bit machine with Intel Xeon E5-2630 v2 processor at $2.60 \mathrm{GHz}$ and 96GB of RAM using Java and CPLEX 12.5.1. Benders reformulations are implemented using the lazy constraint callback function available in CPLEX. We set a time limit of ten hours. All solution times are given in seconds.

\subsection{The changes in the transportation costs and hub locations}

First we compare the hub location decisions made for each uncertainty set and their total transportation costs. In Table 1 , we present results of different uncertainty sets using the CAB data set instances with 25 nodes, $p \in\{2,3,4,5\}$ and $\alpha \in$ $\{0.2,0.4,0.6,0.8\}$. We obtained these results by solving our models using the solver CPLEX. For each $p, \alpha$ and uncertainty set, we report the optimal value and the locations of hubs in the optimal solutions.

When we compare the hub locations of the deterministic model, with those of the hose model, we see that there has been a change in the hub locations in 12 out of 16 instances. The hubs that are closed are usually replaced with a nearby alternative. For example, in the instance with $p=3$ and $\alpha=0.4$, the hubs are installed in Chicago (4), Los Angeles (12) and New York (17) in the deterministic model, whereas the hub at Chicago (4) is replaced with a hub at Cincinnati (5) in the hose model solution. The hub locations of some instances shift several times as the uncertainty set enlarges. Consider the instance with $p=3$ and $\alpha=0.2$. In the deterministic case, hubs are installed at Los Angeles (12), New York (17) and St. Louis (21). As we switch to hybrid uncertainty set with $\psi=0.4$, Chicago (4) replaces St. Louis (21) in the optimal solution; whereas Chicago (4) is replaced with Cincinnati (5) in the hose model solution. Some instances are more sensitive to the demand model changes. The optimal hub locations of the instance with $p=3$ and $\alpha=0.8$ change for the hybrid models with $\psi=0.2,0.4,0.8,1,2$ and the hose model. Moreover, the optimal hub locations for some instances change for the hybrid model, but not the hose model. In the instance with $p=2$ and $\alpha=0.6$, the hubs are located at Los Angeles (12) and Pittsburgh (20) for both deterministic and the hose models. However, considering the hybrid models with $\psi=0.6,0.8,1$, the hub at Los Angeles (12) is moved to Denver (8).

We further observe that for larger values of transfer cost factor $\alpha$, hub locations in the optimal solution are more likely to change for different demand uncertainty sets. The instances with no hub location change generally have smaller $\alpha$ values. For $p=2$, none of the instances with $\alpha \in\{0.2,0.4\}$ has a change in the hub locations. Considering $p=5$, only the hub locations of the instance with the smallest $\alpha$ value, which is 0.2 , remain unchanged. On the other hand, the CAB data set instances do not display any patterns depending on the value of $p$. All instances with $p=3,4$ have a change in the hub 
Table 4

Cost analysis for the TR data set.

\begin{tabular}{|c|c|c|c|c|c|c|c|c|c|}
\hline \multirow[b]{2}{*}{$\mathrm{p}$} & \multirow[b]{2}{*}{$\alpha$} & \multirow[b]{2}{*}{ Deterministic } & \multicolumn{7}{|c|}{ Cost and Percentage deviation from the optimal value } \\
\hline & & & $\begin{array}{l}\text { Hybrid } \\
(\psi=0.2)\end{array}$ & $\begin{array}{l}\text { Hybrid } \\
(\psi=0.4)\end{array}$ & $\begin{array}{l}\text { Hybrid } \\
(\psi=0.6)\end{array}$ & $\begin{array}{l}\text { Hybrid } \\
(\psi=0.8)\end{array}$ & $\begin{array}{l}\text { Hybrid } \\
(\psi=1)\end{array}$ & $\begin{array}{l}\text { Hybrid } \\
(\psi=2)\end{array}$ & Hose \\
\hline \multirow[t]{2}{*}{2} & 0.2 & 44,54 & 783544.78 & 796104.52 & 808664.27 & 821224.01 & 833783.75 & 833783.75 & 833783.75 \\
\hline & & & 0.24 & 0.52 & 0.79 & 1.06 & 1.32 & 1.25 & 0.84 \\
\hline \multirow[t]{2}{*}{2} & 0.4 & 38,41 & 840112.66 & 859638.82 & 879164.99 & 898691.15 & 918217.31 & 921559.32 & 930866.70 \\
\hline & & & 0.00 & 0.00 & 0.00 & 0.75 & 1.73 & 2.10 & 3.13 \\
\hline \multirow[t]{2}{*}{2} & 0.6 & 38,41 & 883983.61 & 910747.71 & 937511.82 & 964275.92 & 991040.02 & 1002321.11 & 1022210.03 \\
\hline & & & 0.00 & 0.00 & 1.21 & 2.51 & 3.78 & 4.96 & 7.04 \\
\hline \multirow[t]{2}{*}{2} & 0.8 & 38,41 & 909727.56 & 940782.32 & 971837.08 & 1002891.84 & 1033946.60 & 1062003.87 & 1087904.35 \\
\hline & & & 0.05 & 0.19 & 1.29 & 2.50 & 3.78 & 6.57 & 9.17 \\
\hline \multirow[t]{2}{*}{3} & 0.2 & $12,41,68$ & 669853.39 & 679488.72 & 689124.06 & 698759.40 & 708394.74 & 709086.96 & 710106.96 \\
\hline & & & 0.08 & 0.19 & 0.30 & 0.40 & 0.50 & 0.60 & 0.74 \\
\hline \multirow[t]{2}{*}{3} & 0.4 & $6,41,44$ & 743571.26 & 760945.74 & 778320.22 & 795694.70 & 813069.18 & 813069.18 & 813069.18 \\
\hline & & & 0.00 & 0.00 & 0.00 & 0.00 & 0.10 & 0.10 & 0.10 \\
\hline \multirow[t]{2}{*}{3} & 0.6 & $6,41,44$ & 802850.50 & 827623.94 & 852397.39 & 877170.84 & 901944.28 & 901944.28 & 901944.28 \\
\hline & & & 0.00 & 0.04 & 0.14 & 0.29 & 0.59 & 0.59 & 0.59 \\
\hline \multirow[t]{2}{*}{3} & 0.8 & $6,41,44$ & 845601.96 & 876890.63 & 908179.30 & 939467.96 & 970756.63 & 972720.83 & 972972.74 \\
\hline & & & 0.00 & 0.00 & 0.00 & 0.04 & 0.72 & 0.41 & 0.44 \\
\hline \multirow[t]{2}{*}{4} & 0.2 & $6,34,44,45$ & 580050.10 & 589882.64 & 599715.19 & 609547.74 & 619380.28 & 620309.11 & 620511.25 \\
\hline & & & 0.00 & 0.00 & 0.22 & 0.45 & 0.67 & 0.35 & 0.13 \\
\hline \multirow[t]{2}{*}{4} & 0.4 & $6,34,44,45$ & 676223.28 & 694784.44 & 713345.61 & 731906.77 & 750467.93 & 752020.97 & 752067.33 \\
\hline & & & 0.00 & 0.00 & 0.00 & 0.01 & 0.15 & 0.04 & 0.04 \\
\hline \multirow[t]{2}{*}{4} & 0.6 & $6,34,44,45$ & 756075.41 & 782703.41 & 809331.41 & 835959.40 & 862587.40 & 864553.81 & 864563.66 \\
\hline & & & 0.08 & 0.23 & 0.58 & 0.93 & 1.54 & 0.89 & 0.89 \\
\hline \multirow[t]{2}{*}{4} & 0.8 & $1,3,41,58$ & 812107.62 & 846436.72 & 880765.83 & 915094.93 & 949424.03 & 973930.34 & 1011155.08 \\
\hline & & & 0.05 & 0.35 & 0.64 & 0.97 & 1.70 & 2.76 & 6.33 \\
\hline \multirow[t]{2}{*}{5} & 0.2 & $6,12,34,45,80$ & 501839.91 & 511185.49 & 520531.08 & 529876.66 & 539222.24 & 541268.35 & 541955.19 \\
\hline & & & 0.00 & 0.00 & 0.03 & 0.09 & 0.16 & 0.11 & 0.06 \\
\hline \multirow{2}{*}{5} & 0.4 & $1,6,12,34,45$ & 613491.23 & 631820.52 & 650149.82 & 668479.11 & 686808.41 & 692054.29 & 694136.79 \\
\hline & & & 0.00 & 0.00 & 0.00 & 0.00 & 0.12 & 0.06 & 0.16 \\
\hline \multirow[t]{2}{*}{5} & 0.6 & $1,6,23,34,45$ & 705452.52 & 732485.59 & 759518.65 & 786551.71 & 813584.77 & 820365.80 & 822480.01 \\
\hline & & & 0.00 & 0.06 & 0.30 & 0.58 & 0.85 & 0.42 & 0.11 \\
\hline \multirow[t]{2}{*}{5} & 0.8 & $1,6,23,41,45$ & 780024.31 & 815991.77 & 851959.23 & 887926.70 & 923894.16 & 938903.81 & 941633.65 \\
\hline & & & 0.05 & 0.38 & 0.69 & 0.98 & 1.29 & 1.16 & 0.71 \\
\hline
\end{tabular}

Table 5

Results for AP data set (total transportation cost/hub locations).

\begin{tabular}{|c|c|c|c|c|c|c|c|c|c|}
\hline $\mathrm{n}$ & $\mathrm{p}$ & Deterministic & $\begin{array}{l}\text { Hybrid } \\
(\psi=0.2)\end{array}$ & $\begin{array}{l}\text { Hybrid } \\
(\psi=0.4)\end{array}$ & $\begin{array}{l}\text { Hybrid } \\
(\psi=0.6)\end{array}$ & $\begin{array}{l}\text { Hybrid } \\
(\psi=0.8)\end{array}$ & $\begin{array}{l}\text { Hybrid } \\
(\psi=1)\end{array}$ & $\begin{array}{l}\text { Hybrid } \\
(\psi=2)\end{array}$ & Hose \\
\hline \multirow[t]{8}{*}{25} & \multirow[t]{2}{*}{2} & 161302.58 & 165060.80 & 168819.02 & 172577.24 & 176335.46 & 180093.68 & 187247.20 & 203814.57 \\
\hline & & 8,18 & 8,18 & 8,18 & 8,18 & 8,18 & 8,18 & 8,18 & 8,18 \\
\hline & \multirow[t]{2}{*}{3} & 143324.89 & 147422.11 & 151519.33 & 155317.65 & 158889.51 & 162461.37 & 168723.49 & 182598.15 \\
\hline & & $2,8,18$ & $2,8,18$ & $2,8,18$ & $7,14,18$ & $7,14,18$ & $7,14,18$ & $7,14,18$ & $7,14,18$ \\
\hline & \multirow[t]{2}{*}{4} & 129326.76 & 133170.64 & 137000.41 & 140830.19 & 144659.96 & 148172.11 & 154566.97 & 166162.91 \\
\hline & & $2,8,18,20$ & $2,8,15,18$ & $2,8,15,18$ & $2,8,15,18$ & $2,8,15,18$ & $7,14,17,18$ & $2,12,14,18$ & $2,8,15,18$ \\
\hline & \multirow[t]{2}{*}{5} & 115391.48 & 119026.66 & 122661.84 & 126292.66 & 129914.99 & 133537.32 & 139672.40 & 152274.07 \\
\hline & & $2,8,17,18,20$ & $2,8,17,18,20$ & $2,8,17,18,20$ & $2,8,15,17,18$ & $2,8,15,17,18$ & $2,8,15,17,18$ & $2,8,17,18,20$ & 2,8,15,16,18 \\
\hline \multirow[t]{8}{*}{40} & \multirow[t]{2}{*}{2} & 167111.47 & 171404.41 & 175697.36 & 179990.31 & 184283.25 & 188576.20 & 196166.30 & 209111.18 \\
\hline & & 12,28 & 12,28 & 12,28 & 12,28 & 12,28 & 12,28 & 12,29 & 12,29 \\
\hline & \multirow[t]{2}{*}{3} & 149821.91 & 153747.16 & 157672.41 & 161597.66 & 165522.92 & 169448.17 & 176035.95 & 189952.43 \\
\hline & & $12,23,28$ & $12,23,28$ & $12,23,28$ & $12,23,28$ & $12,23,28$ & $12,23,28$ & $12,23,28$ & $12,23,28$ \\
\hline & \multirow[t]{2}{*}{4} & 135798.16 & 139463.84 & 143129.51 & 146795.19 & 150460.86 & 154126.54 & 160622.60 & 176189.84 \\
\hline & & $12,23,26,28$ & $12,23,26,28$ & $12,23,26,28$ & $12,23,26,28$ & $12,23,26,28$ & $12,23,26,28$ & $12,23,26,28$ & $12,23,26,28$ \\
\hline & \multirow[t]{2}{*}{5} & 126356.39 & 129982.82 & 133609.26 & 137235.70 & 140862.14 & 144488.57 & 150883.31 & 165649.37 \\
\hline & & $3,13,23,26,28$ & $3,13,23,26,28$ & $3,13,23,26,28$ & $3,13,23,26,28$ & $3,13,23,26,28$ & $3,13,23,26,28$ & $3,13,23,26,28$ & $3,13,23,26,28$ \\
\hline \multirow[t]{8}{*}{50} & \multirow[t]{2}{*}{2} & 168991.03 & 173131.97 & 177272.91 & 181413.84 & 185554.78 & 189695.72 & 197309.05 & 211318.98 \\
\hline & & 15,35 & 15,35 & 15,35 & 15,35 & 15,35 & 15,35 & 15,36 & 14,36 \\
\hline & \multirow[t]{2}{*}{3} & 151329.99 & 155228.15 & 159126.30 & 163024.46 & 166922.61 & 170820.77 & 177595.47 & 191842.19 \\
\hline & & $14,28,35$ & $14,28,35$ & $14,28,35$ & $14,28,35$ & $14,28,35$ & $14,28,35$ & $14,28,35$ & $14,29,35$ \\
\hline & \multirow[t]{2}{*}{4} & 137087.13 & 140720.60 & 144354.06 & 147987.53 & 151620.99 & 155254.45 & 161910.24 & 177383.68 \\
\hline & & $14,28,32,35$ & $14,28,32,35$ & $14,28,32,35$ & $14,28,32,35$ & $14,28,32,35$ & $14,28,32,35$ & $14,28,32,35$ & $14,28,32,35$ \\
\hline & \multirow[t]{2}{*}{5} & 126236.27 & 130029.85 & 133816.84 & 137577.93 & 141339.02 & 145100.10 & 151722.01 & 166131.78 \\
\hline & & $4,14,28,32,35$ & $4,14,28,32,35$ & $4,15,28,32,35$ & $4,15,28,32,35$ & $4,15,28,32,35$ & $4,15,28,32,35$ & $4,15,28,32,35$ & $4,15,28,32,35$ \\
\hline
\end{tabular}


Table 6

Cost analysis for the AP data set.

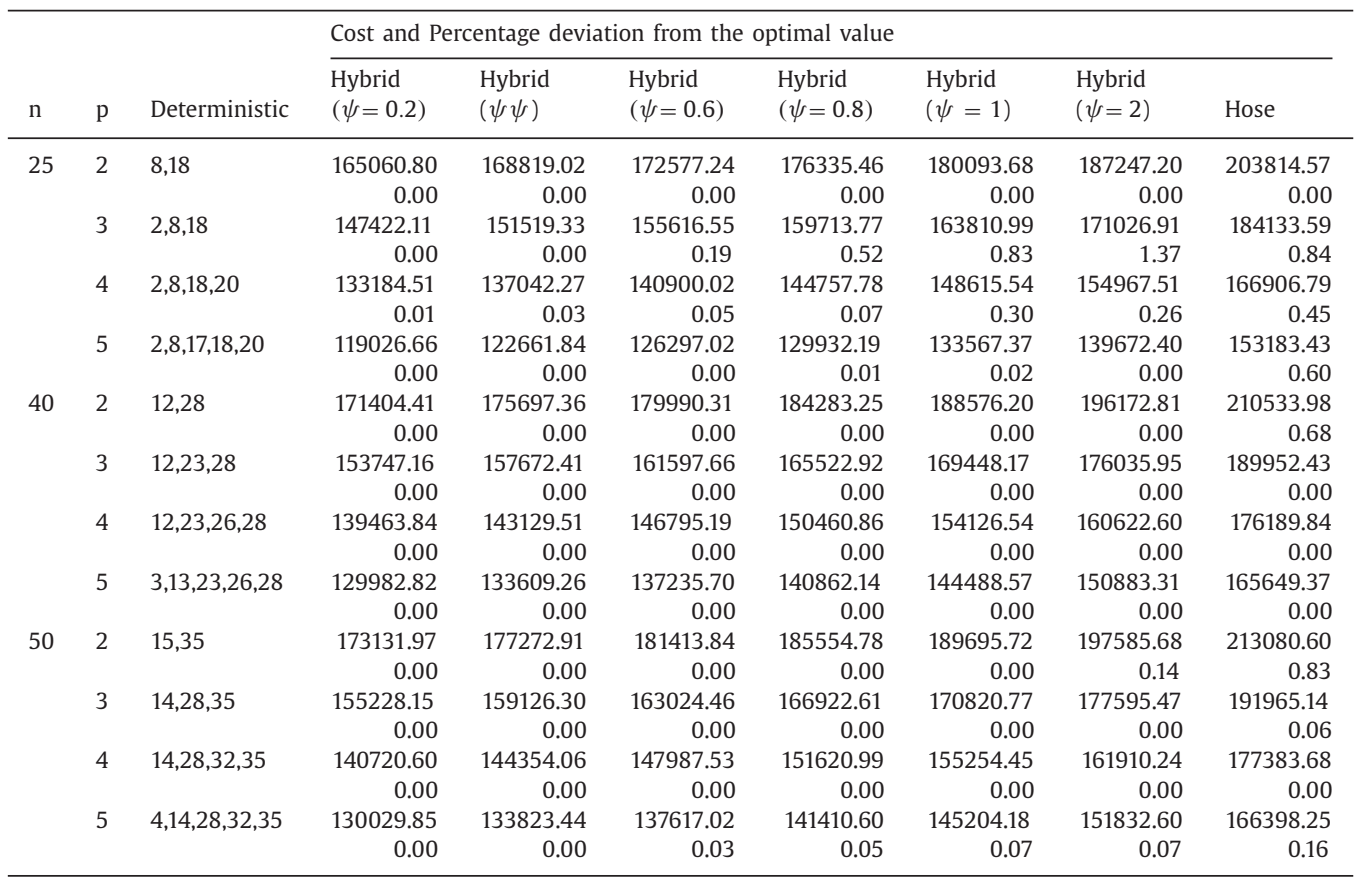

Table 7

Effects of estimated traffic bound values on optimal solutions.

\begin{tabular}{|c|c|c|c|c|c|}
\hline $\mathrm{p}$ & $\alpha$ & Hose & Hose - s1 & Hose - s2 & Hose - s3 \\
\hline \multirow[t]{8}{*}{2} & \multirow[t]{2}{*}{0.2} & 1054.99 & 1031.35 & 1054.53 & 1137.88 \\
\hline & & 12,20 & 12,20 & 12,20 & 12,20 \\
\hline & \multirow[t]{2}{*}{0.4} & 1190.79 & 1163.10 & 1176.44 & 1282.45 \\
\hline & & 12,20 & 12,20 & 12,20 & 12,20 \\
\hline & \multirow[t]{2}{*}{0.6} & 1319.78 & 1288.30 & 1291.16 & 1419.79 \\
\hline & & 12,20 & 12,20 & 12,20 & 12,20 \\
\hline & \multirow[t]{2}{*}{0.8} & 1418.84 & 1387.07 & 1388.50 & 1531.55 \\
\hline & & 5,12 & 5,12 & 12,20 & 8,20 \\
\hline \multirow[t]{8}{*}{3} & \multirow[t]{2}{*}{0.2} & 845.26 & 825.83 & 830.05 & 898.68 \\
\hline & & $5,12,17$ & $5,12,17$ & $5,12,17$ & $5,12,17$ \\
\hline & \multirow[t]{2}{*}{0.4} & 1037.64 & 1012.31 & 1018.87 & 1114.02 \\
\hline & & $5,12,17$ & $5,12,17$ & $5,12,17$ & $5,12,17$ \\
\hline & \multirow[t]{2}{*}{0.6} & 1213.09 & 1183.01 & 1191.89 & 1312.00 \\
\hline & & $5,12,17$ & $5,12,17$ & $5,12,17$ & $5,12,17$ \\
\hline & \multirow[t]{2}{*}{0.8} & 1367.93 & 1336.20 & 1346.11 & 1486.48 \\
\hline & & $5,12,17$ & $5,12,17$ & $5,12,17$ & $5,8,17$ \\
\hline \multirow[t]{8}{*}{4} & \multirow[t]{2}{*}{0.2} & 726.44 & 715.83 & 710.79 & 771.67 \\
\hline & & $4,12,14,17$ & $4,12,14,17$ & $4,12,17,24$ & $4,12,14,17$ \\
\hline & \multirow[t]{2}{*}{0.4} & 967.16 & 949.35 & 947.22 & 1027.38 \\
\hline & & $5,12,14,17$ & $5,12,14,17$ & $5,12,14,17$ & $5,12,14,17$ \\
\hline & \multirow[t]{2}{*}{0.6} & 1170.07 & 1142.48 & 1145.68 & 1259.47 \\
\hline & & $5,12,17,24$ & $5,12,17,24$ & $5,12,17,24$ & $5,12,14,17$ \\
\hline & \multirow[t]{2}{*}{0.8} & 1343.21 & 1311.24 & 1323.50 & 1455.14 \\
\hline & & $5,12,17,22$ & $5,12,17,22$ & $4,5,12,17$ & $5,12,17,22$ \\
\hline \multirow[t]{8}{*}{5} & \multirow[t]{2}{*}{0.2} & 646.72 & 637.16 & 632.34 & 689.23 \\
\hline & & $4,7,12,14,17$ & $4,7,12,14,17$ & $4,7,12,14,17$ & $4,7,12,14,17$ \\
\hline & \multirow[t]{2}{*}{0.4} & 914.1 & 889.39 & 888.91 & 972.43 \\
\hline & & $1,4,12,17,20$ & $1,4,12,17,20$ & $1,4,12,17,20$ & $12,14,17,20,21$ \\
\hline & \multirow[t]{2}{*}{0.6} & 1129.91 & 1102.15 & 1102.61 & 1218.52 \\
\hline & & $5,8,12,17,24$ & $5,8,12,17,24$ & $1,4,12,17,20$ & $5,8,12,14,17$ \\
\hline & \multirow[t]{2}{*}{0.8} & 1322.23 & 1292.20 & 1296.0493 & 1429.30 \\
\hline & & $5,12,14,17,22$ & $5,12,17,22,24$ & $1,4,12,17,20$ & $5,12,14,17,22$ \\
\hline
\end{tabular}


Table 8

Effects of estimated traffic bound values on optimal solutions - Dallas (7).

\begin{tabular}{|c|c|c|c|c|c|c|c|c|c|c|}
\hline $\mathrm{p}$ & $\alpha$ & $\Delta=-0.8$ & $\Delta=-0.6$ & $\Delta=-0.4$ & $\Delta=-0.2$ & $\Delta=0$ & $\Delta=0.2$ & $\Delta=0.4$ & $\Delta=0.6$ & $\Delta=0.8$ \\
\hline \multirow[t]{8}{*}{2} & \multirow[t]{2}{*}{0.2} & 1003.40 & 1016.30 & 1029.19 & 1042.09 & 1054.99 & 1067.88 & 1080.78 & 1093.68 & 1106.57 \\
\hline & & 12,20 & 12,20 & 12,20 & 12,20 & 12,20 & 12,20 & 12,20 & 12,20 & 12,20 \\
\hline & \multirow[t]{2}{*}{0.4} & 1139.21 & 1152.10 & 1165.00 & 1177.90 & 1190.79 & 1203.69 & 1216.59 & 1229.48 & 1242.38 \\
\hline & & 12,20 & 12,20 & 12,20 & 12,20 & 12,20 & 12,20 & 12,20 & 12,20 & 12,20 \\
\hline & \multirow[t]{2}{*}{0.6} & 1268.19 & 1281.09 & 1293.99 & 1306.88 & 1319.78 & 1332.68 & 1342.54 & 1352.30 & 1362.07 \\
\hline & & 12,20 & 12,20 & 12,20 & 12,20 & 12,20 & 12,20 & 5,12 & 5,12 & 5,12 \\
\hline & \multirow[t]{2}{*}{0.8} & 1378.39 & 1389.56 & 1399.32 & 1409.08 & 1418.84 & 1428.60 & 1438.36 & 1448.12 & 1457.89 \\
\hline & & 8,20 & 5,12 & 5,12 & 5,12 & 5,12 & 5,12 & 5,12 & 5,12 & 5,12 \\
\hline \multirow[t]{8}{*}{3} & \multirow[t]{2}{*}{0.2} & 806.16 & 815.94 & 825.72 & 835.50 & 845.26 & 855.03 & 864.79 & 874.55 & 884.31 \\
\hline & & $5,12,17$ & $5,12,17$ & $5,12,17$ & $5,12,17$ & $5,12,17$ & $5,12,17$ & $5,12,17$ & $5,12,17$ & $5,12,17$ \\
\hline & \multirow[t]{2}{*}{0.4} & 998.59 & 1008.36 & 1018.12 & 1027.88 & 1037.64 & 1047.40 & 1057.16 & 1066.92 & 1076.69 \\
\hline & & $5,12,17$ & $5,12,17$ & $5,12,17$ & $5,12,17$ & $5,12,17$ & $5,12,17$ & $5,12,17$ & $5,12,17$ & $5,12,17$ \\
\hline & \multirow[t]{2}{*}{0.6} & 1174.04 & 1183.80 & 1193.56 & 1203.33 & 1213.09 & 1222.85 & 1232.61 & 1242.37 & 1252.13 \\
\hline & & $5,12,17$ & $5,12,17$ & $5,12,17$ & $5,12,17$ & $5,12,17$ & $5,12,17$ & $5,12,17$ & $5,12,17$ & $5,12,17$ \\
\hline & \multirow[t]{2}{*}{0.8} & 1328.88 & 1338.64 & 1348.40 & 1358.17 & 1367.93 & 1377.69 & 1387.45 & 1397.21 & 1406.97 \\
\hline & & $5,12,17$ & $5,12,17$ & $5,12,17$ & $5,12,17$ & $5,12,17$ & $5,12,17$ & $5,12,17$ & $5,12,17$ & $5,12,17$ \\
\hline \multirow[t]{8}{*}{4} & \multirow[t]{2}{*}{0.2} & 687.55 & 697.28 & 707.00 & 716.72 & 726.44 & 736.17 & 745.89 & 755.61 & 765.34 \\
\hline & & $4,12,14,17$ & $4,12,14,17$ & $4,12,14,17$ & $4,12,14,17$ & $4,12,14,17$ & $4,12,14,17$ & $4,12,14,17$ & $4,12,14,17$ & $4,12,14,17$ \\
\hline & \multirow[t]{2}{*}{0.4} & 927.97 & 937.77 & 947.57 & 957.37 & 967.16 & 976.96 & 986.76 & 996.55 & 1002.10 \\
\hline & & $5,12,14,17$ & $5,12,14,17$ & $5,12,14,17$ & $5,12,14,17$ & $5,12,14,17$ & $5,12,14,17$ & $5,12,14,17$ & $5,12,14,17$ & $5,7,12,17$ \\
\hline & \multirow[t]{2}{*}{0.6} & 1131.02 & 1140.78 & 1150.54 & 1160.30 & 1170.07 & 1179.83 & 1189.59 & 1198.54 & 1204.36 \\
\hline & & $5,12,17,24$ & $5,12,17,24$ & $5,12,17,24$ & $5,12,17,24$ & $5,12,17,24$ & $5,12,17,24$ & $5,12,17,24$ & $5,7,12,17$ & $5,7,12,17$ \\
\hline & \multirow[t]{2}{*}{0.8} & 1304.16 & 1313.92 & 1323.68 & 1333.44 & 1343.21 & 1352.97 & 1362.73 & 1372.49 & 1382.25 \\
\hline & & $5,12,17,22$ & $5,12,17,22$ & $5,12,17,22$ & $5,12,17,22$ & $5,12,17,22$ & $5,12,17,22$ & $5,12,17,22$ & $5,12,17,22$ & $5,12,17,22$ \\
\hline \multirow[t]{8}{*}{5} & \multirow[t]{2}{*}{0.2} & 632.47 & 638.41 & 643.20 & 644.96 & 646.72 & 648.48 & 650.24 & 652.00 & 653.76 \\
\hline & & $4,12,13,14,17$ & $4,12,13,14,17$ & $4,7,12,14,17$ & $4,7,12,14,17$ & $4,7,12,14,17$ & $4,7,12,14,17$ & $4,7,12,14,17$ & $4,7,12,14,17$ & $4,7,12,14,17$ \\
\hline & \multirow[t]{2}{*}{0.4} & 872.15 & 882.63 & 893.12 & 903.61 & 914.1 & 918.78 & 922.30 & 925.83 & 929.35 \\
\hline & & $1,4,12,17,20$ & $1,4,12,17,20$ & $1,4,12,17,20$ & $1,4,12,17,20$ & $1,4,12,17,20$ & $4,7,12,14,17$ & $4,7,12,14,17$ & $4,7,12,14,17$ & $4,7,12,14,17$ \\
\hline & \multirow[t]{2}{*}{0.6} & 1088.39 & 1099.77 & 1110.28 & 1120.09 & 1129.91 & 1139.72 & 1149.49 & 1155.31 & 1161.13 \\
\hline & & $1,4,12,17,20$ & $1,4,12,17,20$ & $5,8,12,17,24$ & $5,8,12,17,24$ & $5,8,12,17,24$ & $5,8,12,17,24$ & $5,7,12,17,24$ & $5,7,12,17,24$ & $5,7,12,17,24$ \\
\hline & \multirow[t]{2}{*}{0.8} & 1283.19 & 1292.95 & 1302.71 & 1312.47 & 1322.23 & 1331.99 & 1341.75 & 1351.52 & 1361.28 \\
\hline & & $5,12,14,17,22$ & $5,12,14,17,22$ & $5,12,14,17,22$ & $5,12,14,17,22$ & $5,12,14,17,22$ & $5,12,14,17,22$ & $5,12,14,17,22$ & $5,12,14,17,22$ & $5,12,14,17,22$ \\
\hline
\end{tabular}

locations while there are instances with no change with $p=2$, 5. It is difficult to draw any conclusions about the effects of $p$ value on the optimal hub locations for different uncertainty sets.

We observe, in Table 1, that the changes in the locations of hubs are not major. Another important aspect to be considered is the performance of deterministic hub location decisions under different demand realizations. In Table 2, we analyze, for the CAB data set, how the total cost will be affected if hubs are selected based on the deterministic model but the demand changes with one of the proposed uncertainty sets. We report the worst case costs using deterministic hub locations under different uncertainty sets and the percentage deviations from the optimal values. It can be observed that the deviation from the optimal value usually increases as $\alpha$ grows and the uncertainty set enlarges. However, there are some instances that does not follow this pattern. For example, the instance with $p=2$ and $\alpha=0.8$ has its largest deviation (4.11\%) in the hybrid model with $\psi=1$ which is significantly greater than the deviation in the corresponding hose model solution $(0.81 \%)$. In addition, we observe that by incorporating uncertainty into the decision making process, we can make savings of up to $4.11 \%$ in the total cost.

We perform the same location and cost analysis also on the TR data set instances. Table 3 presents the optimal hub locations and corresponding total transportation costs under different demand uncertainty model settings. Considering the hub locations, it can be seen that the TR data set is more sensitive to the changes in the demand. For all 16 instances, there has been a change in the hub locations in response to the demand model changes. In six of them, the hub location change occurs in the least conservative model with the demand uncertainty (hybrid model with $\psi=0.2$ ). 11 instances out of 16 are exposed to changes in the hub locations under hybrid uncertainty models with $\psi$ value up to 0.6. In the TR data, the cities Ankara (6), İstanbul (34) and İzmir (35) are the ones with the largest demand values. We observe that as the uncertainty set enlarges, these cities are more likely to be in the set of optimal hub locations. For example, with parameters $p=2$ and $\alpha=0.4,0.6,0.8$, the deterministic model chooses Kayseri (38) and Kocaeli (41) as hub locations while the hose model chooses Ankara (6) in all three instances and İstanbul (34) in one of them. Additionally, from Tables 1 and 3 , it can be seen that the optimal value of the hybrid model converges to the optimal value of the hose model as $\psi$ and consequently the upper bounds on the pairwise demands increases. Considering TR data set instance with $p=2$ and $\alpha=0.4$, the optimal solution value of the hybrid model increases as $\psi$ grows and ultimately becomes equal to the optimal value of the hose model when $\psi=1$.

We also investigate how the total transportation cost is affected as we change the demand uncertainty model using the TR data set instances. In Table 4, the deterministic model optimal hub locations, their total transportation costs under dif- 
Table 9

Effects of estimated traffic bound values on optimal solutions - Los Angeles (12).

\begin{tabular}{|c|c|c|c|c|c|c|c|c|c|c|}
\hline $\mathrm{p}$ & $\alpha$ & $\Delta=-0.8$ & $\Delta=-0.6$ & $\Delta=-0.4$ & $\Delta=-0.2$ & $\Delta=0$ & $\Delta=0.2$ & $\Delta=0.4$ & $\Delta=0.6$ & $\Delta=0.8$ \\
\hline \multirow[t]{8}{*}{2} & \multirow[t]{2}{*}{0.2} & 983.79 & 1007.54 & 1030.13 & 1042.56 & 1054.99 & 1067.42 & 1079.8433 & 1092.27 & 1104.70 \\
\hline & & 20,22 & 20,22 & 12,20 & 12,20 & 12,20 & 12,20 & 12,20 & 12,20 & 12,20 \\
\hline & \multirow[t]{2}{*}{0.4} & 1073.26 & 1110.18 & 1141.08 & 1165.94 & 1190.79 & 1215.65 & 1240.5048 & 1265.36 & 1290.22 \\
\hline & & 20,22 & 20,22 & 12,20 & 12,20 & 12,20 & 12,20 & 12,20 & 12,20 & 12,20 \\
\hline & \multirow[t]{2}{*}{0.6} & 1145.44 & 1192.88 & 1240.31 & 1282.50 & 1319.78 & 1356.17 & 1389.3101 & 1422.46 & 1455.60 \\
\hline & & 8,20 & 8,20 & 8,20 & 12,20 & 12,20 & 5,12 & 5,12 & 5,12 & 5,12 \\
\hline & \multirow[t]{2}{*}{0.8} & 1209.79 & 1264.84 & 1319.88 & 1374.65 & 1418.84 & 1463.03 & 1507.2273 & 1551.42 & 1595.61 \\
\hline & & 8,20 & 8,20 & 8,20 & 5,12 & 5,12 & 5,12 & 5,12 & 5,12 & 5,12 \\
\hline \multirow[t]{8}{*}{3} & \multirow[t]{2}{*}{0.2} & 778.65 & 801.12 & 823.17 & 834.22 & 845.26 & 856.29 & 867.291 & 878.30 & 889.30 \\
\hline & & $5,17,22$ & $5,17,22$ & $5,12,17$ & $5,12,17$ & $5,12,17$ & $5,12,17$ & $5,12,17$ & $5,12,17$ & $5,12,17$ \\
\hline & \multirow[t]{2}{*}{0.4} & 932.65 & 967.03 & 993.45 & 1015.54 & 1037.64 & 1059.74 & 1081.8331 & 1103.93 & 1126.03 \\
\hline & & $5,17,22$ & $5,17,22$ & $5,12,17$ & $5,12,17$ & $5,12,17$ & $5,12,17$ & $5,12,17$ & $5,12,17$ & $5,12,17$ \\
\hline & \multirow[t]{2}{*}{0.6} & 1062.15 & 1105.70 & 1146.80 & 1179.94 & 1213.09 & 1246.23 & 1279.3771 & 1312.52 & 1345.67 \\
\hline & & $5,8,17$ & $5,8,17$ & $5,12,17$ & $5,12,17$ & $5,12,17$ & $5,12,17$ & $5,12,17$ & $5,12,17$ & $5,12,17$ \\
\hline & \multirow[t]{2}{*}{0.8} & 1174.58 & 1224.46 & 1274.33 & 1323.73 & 1367.93 & 1412.12 & 1456.3135 & 1500.51 & 1544.70 \\
\hline & & $5,8,17$ & $5,8,17$ & $5,8,17$ & $5,12,17$ & $5,12,17$ & $5,12,17$ & $5,12,17$ & $5,12,17$ & $5,12,17$ \\
\hline \multirow[t]{8}{*}{4} & \multirow[t]{2}{*}{0.2} & 661.33 & 683.63 & 705.04 & 716.29 & 726.44 & 736.60 & 746.7622 & 756.92 & 767.08 \\
\hline & & $1,4,17,22$ & $4,14,17,22$ & $4,14,17,22$ & $4,12,14,17$ & $4,12,14,17$ & $4,12,14,17$ & $4,12,14,17$ & $4,12,14,17$ & $4,12,14,17$ \\
\hline & \multirow[t]{2}{*}{0.4} & 860.86 & 896.39 & 923.14 & 945.15 & 967.16 & 989.17 & 1009.8306 & 1030.15 & 1050.47 \\
\hline & & $1,4,17,22$ & $1,4,17,22$ & $5,12,14,17$ & $5,12,14,17$ & $5,12,14,17$ & $5,12,14,17$ & $4,12,14,17$ & $4,12,14,17$ & $4,12,14,17$ \\
\hline & \multirow[t]{2}{*}{0.6} & 1019.13 & 1062.68 & 1103.78 & 1136.92 & 1170.07 & 1203.21 & 1236.3555 & 1269.50 & 1302.51 \\
\hline & & $5,8,17,24$ & $5,8,17,24$ & $5,12,17,24$ & $5,12,17,24$ & $5,12,17,24$ & $5,12,17,24$ & $5,12,17,24$ & $5,12,17,24$ & $5,12,17,24$ \\
\hline & \multirow[t]{2}{*}{0.8} & 1152.54 & 1203.13 & 1253.36 & 1299.01 & 1343.21 & 1387.40 & 1431.5927 & 1475.79 & 1519.98 \\
\hline & & $5,8,17,20$ & $5,8,17,20$ & $5,8,14,17$ & $5,12,17,22$ & $5,12,17,22$ & $5,12,17,22$ & $5,12,17,22$ & $5,12,17,22$ & $5,12,17,22$ \\
\hline \multirow[t]{8}{*}{5} & \multirow[t]{2}{*}{0.2} & 580.75 & 602.59 & 624.43 & 636.16 & 646.72 & 657.29 & 667.6689 & 677.83 & 687.99 \\
\hline & & $4,7,14,17,22$ & $4,7,14,17,22$ & $4,7,14,17,22$ & $4,7,12,14,17$ & $4,7,12,14,17$ & $4,7,12,14,17$ & $4,7,12,14,17$ & $4,7,12,14,17$ & $4,7,12,14,17$ \\
\hline & \multirow{2}{*}{0.4} & 803.29 & 837.75 & 868.02 & 891.06 & 914.1 & 936.39 & 957.5181 & 977.93 & 998.25 \\
\hline & & $1,4,17,20,22$ & $4,7,14,17,22$ & $1,4,12,17,20$ & $1,4,12,17,20$ & $1,4,12,17,20$ & $4,7,12,14,17$ & $4,7,12,14,17$ & $4,7,12,14,17$ & $4,7,12,14,17$ \\
\hline & \multirow[t]{2}{*}{0.6} & 980.43 & 1023.99 & 1063.87 & 1096.89 & 1129.91 & 1162.92 & 1195.9407 & 1228.96 & 1261.98 \\
\hline & & $5,8,17,22,24$ & $5,8,17,22,24$ & $5,8,12,17,24$ & $5,8,12,17,24$ & $5,8,12,17,24$ & $5,8,12,17,24$ & $5,8,12,17,24$ & $5,8,12,17,24$ & $5,8,12,17,24$ \\
\hline & \multirow[t]{2}{*}{0.8} & 1129.65 & 1182.16 & 1232.75 & 1278.04 & 1322.23 & 1366.42 & 1410.6181 & 1454.81 & 1499.00 \\
\hline & & $1,4,17,20,22$ & $5,8,14,17,20$ & $5,8,14,17,20$ & $5,12,14,17,22$ & $5,12,14,17,22$ & $5,12,14,17,22$ & $5,12,14,17,22$ & $5,12,14,17,22$ & $5,12,14,17,22$ \\
\hline
\end{tabular}

ferent uncertainty models and the percentage deviations from the optimal value of the corresponding model are presented. It can be seen that the deterministic model solutions perform well under the hybrid demand uncertainty with $\psi$ value up to 0.6 ; the deviation from the optimal value is within less than $1.5 \%$. However, for larger uncertainty sets, the total cost can be subject to an increase of up to $10 \%$. Four of the instances under the hose model show percentage increase in the total transportation costs with 3.13\%, 7.04\%, 9.17\% and 6.33\%, respectively. An interesting observation is that for these instances, Ankara (6), İstanbul (34) and İzmir (35) are not selected as hub nodes in the deterministic model, unlike the hose model. It can be concluded that, in these instances, the cost of uncertainty may increase significantly when the nodes with large inbound and outbound traffic are not chosen as hubs.

We obtained similar results after performing cost and location analysis for the AP data set instances. In Table 5, we present the optimal transportation costs and hub locations under different demand models. There is a change in the optimal hub locations in 7 out of $12 \mathrm{AP}$ data set instances. Again it can be seen that there is no pattern in the variations in the hub locations depending on the value of $p$. For the instances with 25 nodes, there exists a change in the optimal hub locations in all except the one with $p=2$. On the other hand, considering the instances with 40 nodes, the only instance that shows a change in the hub locations is the one with $p=2$. In Table 6 , we also provide the analysis of how the optimal hub locations of the deterministic model performs under different demand uncertainty models. In view of our computational results, the AP data set instances turn out to be quite resilient to the uncertainty in the demand. It can be seen that the maximum percentage deviation from the optimal value is $1.37 \%$ and for many instances the percentage deviation is almost zero. This may be because in the AP data set, nodes have more balanced traffic bound values compared to the CAB and TR data sets.

Another important point to be considered is how our estimation of traffic bounds affects the results of our models. To investigate this aspect, we tested the hose model on the CAB data set instances with various traffic bound values. Note that when all traffic bounds are increased or decreased with the same rate, the optimal hub locations stay the same and total transportation costs change proportionally. In order to consider the case where traffic bound for each node deviates with a different rate, we construct three distinct scenarios. In each scenario, nodes are grouped into three based on their former traffic bound values. We set a larger deviation for the group with smaller bounds since smaller amounts are more likely to change with a larger rate. In the first scenario, the nodes in the group with the largest traffic bounds have a rate of change in the interval $[-0.05,0.05]$ uniformly, the second group takes value from the interval $[-0.10,0.10]$ and the third one from $[-0.30,0.30]$. For the second and the third scenarios these intervals are set as $([-0.10,0.10],[-0.20,0.20],[-0.40,0.40])$ and $([-0.15,0.15],[-0.25,0.25],[-0.50,0.50])$, respectively. The optimal total transportation costs and hub locations are reported in 
Table 10

Comparison of exact approaches for hose demand uncertainty - AP instances.

\begin{tabular}{|c|c|c|c|c|c|c|c|c|c|}
\hline \multirow[b]{2}{*}{$n$} & \multirow[b]{2}{*}{$p$} & \multirow[b]{2}{*}{$\begin{array}{l}\text { Optimal } \\
\text { value }\end{array}$} & \multirow[b]{2}{*}{$\begin{array}{l}\text { MIP model } \\
\text { CPU time }\end{array}$} & \multicolumn{3}{|l|}{ Benders 1} & \multicolumn{3}{|l|}{ Benders 2} \\
\hline & & & & $\begin{array}{l}\text { CPU time } \\
\text { (gap) }\end{array}$ & $\begin{array}{l}\text { \# Cuts } \\
\text { added }\end{array}$ & $\begin{array}{l}\text { \# } \\
\text { Callbacks }\end{array}$ & $\begin{array}{l}\text { CPU time } \\
\text { (gap) }\end{array}$ & $\begin{array}{l}\text { \# Cuts } \\
\text { added }\end{array}$ & $\begin{array}{l}\text { \# } \\
\text { Callbacks }\end{array}$ \\
\hline \multirow[t]{3}{*}{40} & 3 & 189952.43 & 1696.29 & 5.37 & 90 & 94 & 1.53 & 7920 & 10 \\
\hline & 4 & 176189.84 & 4901.37 & 20.93 & 332 & 340 & 2.91 & 7437 & 9 \\
\hline & 5 & 165649.37 & 6490.57 & 69.41 & 972 & 985 & 5.14 & 9571 & 17 \\
\hline \multirow[t]{3}{*}{50} & 3 & 191842.19 & 22310.31 & 12.63 & 103 & 109 & 4.54 & 16,932 & 12 \\
\hline & 4 & 177383.68 & $(1.93)$ & 52.27 & 421 & 434 & 6.14 & 16,721 & 12 \\
\hline & 5 & 166131.78 & $(1.70)$ & 148.67 & 1034 & 1045 & 10.86 & 14,418 & 14 \\
\hline \multirow[t]{3}{*}{75} & 3 & 196368.51 & $(100)$ & 89.57 & 170 & 175 & 29.08 & 25,571 & 8 \\
\hline & 4 & 181077.10 & $(100)$ & 285.68 & 537 & 545 & 41.44 & 50,558 & 18 \\
\hline & 5 & 170306.35 & $(100)$ & 999.65 & 1568 & 1581 & 54.04 & 35,986 & 14 \\
\hline \multirow[t]{3}{*}{100} & 3 & 196754.67 & memory & 310.00 & 231 & 236 & 82.01 & 85,402 & 17 \\
\hline & 4 & 181884.09 & memory & 1109.29 & 791 & 804 & 196.37 & 82,644 & 20 \\
\hline & 5 & 172098.88 & memory & 6519.98 & 3122 & 3132 & 669.04 & 102,888 & 25 \\
\hline \multirow[t]{3}{*}{125} & 3 & 197275.77 & memory & 731.11 & 247 & 255 & 257.16 & 141,245 & 17 \\
\hline & 4 & 182518.12 & memory & 2589.21 & 838 & 850 & 490.46 & 198,014 & 31 \\
\hline & 5 & 172420.17 & memory & 15116.85 & 3209 & 3225 & 945.73 & 191,772 & 31 \\
\hline \multirow[t]{3}{*}{150} & 3 & 198361.42 & memory & 1755.15 & 293 & 299 & 715.35 & 257,936 & 26 \\
\hline & 4 & 183373.34 & memory & 6399.51 & 1050 & 1057 & 1470.29 & 222,830 & 18 \\
\hline & 5 & 173381.56 & memory & $(2.20)$ & 3882 & 3896 & 4860.56 & 212,098 & 22 \\
\hline \multirow[t]{3}{*}{200} & 3 & 199944.64 & memory & 6951.20 & 430 & 437 & 4020.22 & 426,417 & 22 \\
\hline & 4 & 185433.91 & memory & $(2.18)$ & 1830 & 1846 & 9332.57 & 490,686 & 31 \\
\hline & 5 & $176175.91 *$ & memory & (7.43) & 1783 & 1798 & $(0.49)$ & 474,147 & 26 \\
\hline
\end{tabular}

Table 7. It can be seen that total transportation costs are slightly lower than the optimal values of the initial hose model instances for scenarios 1 and 2 and larger for scenario 3. Out of 16 instances, there has been a change in the optimal hub locations for five instances in scenario 3 (s3), three in scenario 2 (s2) and only one instance in scenario 1 (s1). The hose model results seem to be quite tolerant to the deviations in the traffic bounds.

We also consider the effects of inaccurate estimation of the traffic bound of a single node on the CAB data set instances. In Tables 8 and 9, we present our results for Dallas (7) and Los Angeles (12), respectively. Among the nodes with the highest traffic bounds, Dallas is the tenth node with 3\% and Los Angeles is the third node with $7 \%$ of the total traffic. For each deviation level $\Delta$, we report optimal transportation cost and optimal hub locations. From these results, it can be seen that as the traffic bound of a node increases, it becomes more likely that a hub is installed closer to that node. For example, in Table 8, considering instance $p=2$ and $\alpha=0.6$, the hub located at Pittsburgh (20) moves to Cincinnati (5) as the traffic bound of Dallas is increased by $40 \%$. In four instances out of 16 , a hub is installed at Dallas (7) due to an increase in the traffic bounds. In Table 9, Los Angeles (12) is selected as a hub for all instances with $\Delta=0$. However, in the case that traffic bound of Los Angeles drops by 40\%, the hub at Los Angeles is moved to another location in seven instances. On the other hand, hub location changes generally occur after a $40 \%$ variation in the demand. Considering Dallas (7) and Los Angeles (12) as average and high level demand nodes respectively, it can be concluded that the hose model results are resistant to fluctuations in the demand of a single node.

In summary, we observed that with minor changes in hub locations, it is possible to hedge against demand uncertainty. When the cost reduction in hub-to-hub transfers is high, demand uncertainty has more impact on the hub locations. Finally, nodes with high traffic bounds are more likely to become hubs or be close to hubs as the level of uncertainty increases.

\subsection{Comparison of exact methods}

Next we analyze the performance of the proposed exact solution methods using AP instances. In Table 10, we present the results obtained for the robust UMApHMP with hose demand uncertainty using the mathematical model, the first Benders decomposition proposed in Section 4.1 (Benders 1) and the Benders decomposition by projecting out flow variables as described in Section 4.2 (Benders 2). We compare the computational effectiveness of each approach in terms of solution times. We also present the number of Benders cuts added and the number of callbacks performed in Benders 1 and Benders 2 until the optimal solution or the best solution obtained within the time limit. Since we use the lazy constraint callback function of the CPLEX, the number of callbacks here implies how many times the lazy constraints are checked during the branch-and-bound process. At each time an incumbent solution is found, associated optimality cuts are added to a cut pool managed by the solver. "\# of Cuts Added" represents the number of optimality cuts added until optimality is achieved. Note that the first Benders approach adds at most a single cut in each iteration whereas in the second, at most $n(n-1)$ cuts can be added. The solutions marked with an asterisk are the best of the solutions obtained within the time limit. For the unsolved instances, instead of the solution time, the optimality gap is reported.

The mixed integer programming model can be solved for instances with at most 50 nodes while Benders decomposition based formulations succeed to solve instances with up to 200 nodes. Benders 1 can not solve three instances out of 21 
Table 11

Comparison of exact approaches for hybrid demand uncertainty - small AP instances.

\begin{tabular}{|c|c|c|c|c|c|c|c|c|c|c|}
\hline \multirow[b]{2}{*}{$n$} & \multirow[b]{2}{*}{$p$} & \multirow[b]{2}{*}{$\psi$} & \multirow[b]{2}{*}{$\begin{array}{l}\text { Optimal } \\
\text { value }\end{array}$} & \multirow[b]{2}{*}{$\begin{array}{l}\text { MIP model } \\
\text { CPU time }\end{array}$} & \multicolumn{3}{|c|}{ Benders 1} & \multicolumn{3}{|c|}{ Benders 2} \\
\hline & & & & & $\begin{array}{l}\mathrm{CPU} \\
\text { time }\end{array}$ & $\begin{array}{l}\# \text { Cuts } \\
\text { added }\end{array}$ & $\begin{array}{l}\# \\
\text { Callbacks }\end{array}$ & $\begin{array}{l}\mathrm{CPU} \\
\text { time }\end{array}$ & $\begin{array}{l}\text { \# Cuts } \\
\text { added }\end{array}$ & $\begin{array}{l}\# \\
\text { Callbacks }\end{array}$ \\
\hline \multirow[t]{18}{*}{40} & 3 & 0.2 & 153747.16 & 92.14 & 14.48 & 73 & 77 & 7.31 & 9734 & 13 \\
\hline & 3 & 0.4 & 157672.41 & 121.64 & 19.82 & 100 & 104 & 6.36 & 8059 & 11 \\
\hline & 3 & 0.6 & 161597.66 & 214.98 & 18.75 & 95 & 101 & 5.82 & 7067 & 9 \\
\hline & 3 & 0.8 & 165522.92 & 350.33 & 20.20 & 108 & 116 & 8.96 & 8226 & 9 \\
\hline & 3 & 1.0 & 169448.17 & 1128.39 & 15.77 & 97 & 103 & 7.59 & 9198 & 14 \\
\hline & 3 & 2.0 & 176035.95 & 1924.03 & 13.85 & 97 & 104 & 10.86 & 9174 & 11 \\
\hline & 4 & 0.2 & 139463.84 & 79.44 & 38.63 & 183 & 188 & 6.44 & 7371 & 8 \\
\hline & 4 & 0.4 & 143129.51 & 81.20 & 44.15 & 216 & 225 & 10.24 & 8422 & 9 \\
\hline & 4 & 0.6 & 146795.19 & 138.11 & 37.54 & 204 & 211 & 6.53 & 7904 & 8 \\
\hline & 4 & 0.8 & 150460.86 & 167.99 & 36.81 & 211 & 220 & 12.23 & 9674 & 12 \\
\hline & 4 & 1.0 & 154126.54 & 922.64 & 46.79 & 279 & 289 & 6.55 & 9037 & 10 \\
\hline & 4 & 2.0 & 160622.60 & 1566.95 & 33.04 & 233 & 241 & 5.64 & 7863 & 9 \\
\hline & 5 & 0.2 & 129982.82 & 75.20 & 90.13 & 440 & 448 & 5.92 & 9248 & 12 \\
\hline & 5 & 0.4 & 133609.26 & 102.48 & 101.98 & 499 & 510 & 8.74 & 8657 & 8 \\
\hline & 5 & 0.6 & 137235.70 & 176.89 & 114.02 & 559 & 569 & 12.86 & 10,077 & 15 \\
\hline & 5 & 0.8 & 140862.14 & 320.06 & 117.21 & 624 & 634 & 18.19 & 10,437 & 14 \\
\hline & 5 & 1.0 & 144488.57 & 1308.45 & 111.63 & 634 & 642 & 8.39 & 8193 & 10 \\
\hline & 5 & 2.0 & 150883.31 & 2074.97 & 99.42 & 689 & 699 & 15.80 & 7764 & 8 \\
\hline \multirow{18}{*}{50} & 3 & 0.2 & 155228.15 & 495.82 & 30.15 & 104 & 112 & 16.03 & 15,462 & 14 \\
\hline & 3 & 0.4 & 159126.30 & 680.51 & 31.94 & 115 & 121 & 23.80 & 14,787 & 14 \\
\hline & 3 & 0.6 & 163024.46 & 1308.55 & 36.52 & 124 & 133 & 25.26 & 13,948 & 10 \\
\hline & 3 & 0.8 & 166922.61 & 1635.23 & 36.04 & 125 & 133 & 24.21 & 14,554 & 11 \\
\hline & 3 & 1.0 & 170820.77 & 11089.81 & 33.96 & 119 & 125 & 30.52 & 16,151 & 11 \\
\hline & 3 & 2.0 & 177595.47 & 23037.79 & 41.90 & 154 & 164 & 43.42 & 20,128 & 16 \\
\hline & 4 & 0.2 & 140720.60 & 350.84 & 72.92 & 258 & 265 & 20.88 & 15,936 & 13 \\
\hline & 4 & 0.4 & 144354.06 & 430.25 & 74.70 & 259 & 268 & 21.64 & 16,615 & 12 \\
\hline & 4 & 0.6 & 147987.53 & 499.01 & 75.89 & 262 & 272 & 23.42 & 16,757 & 14 \\
\hline & 4 & 0.8 & 151620.99 & 1132.57 & 83.17 & 287 & 295 & 32.97 & 13,563 & 12 \\
\hline & 4 & 1.0 & 155254.45 & 4467.07 & 84.23 & 290 & 302 & 21.12 & 15,511 & 11 \\
\hline & 4 & 2.0 & 161910.24 & 5585.95 & 82.31 & 300 & 310 & 34.95 & 14,725 & 10 \\
\hline & 5 & 0.2 & 130029.85 & 440.22 & 145.28 & 482 & 493 & 29.94 & 16,715 & 18 \\
\hline & 5 & 0.4 & 133816.84 & 604.71 & 155.34 & 536 & 543 & 64.05 & 15,333 & 12 \\
\hline & 5 & 0.6 & 137577.93 & 651.43 & 179.25 & 588 & 598 & 48.70 & 14,081 & 11 \\
\hline & 5 & 0.8 & 141339.02 & 1212.00 & 207.58 & 672 & 684 & 61.76 & 15,423 & 16 \\
\hline & 5 & 1.0 & 145100.10 & 5370.77 & 222.32 & 722 & 733 & 62.97 & 14,736 & 13 \\
\hline & 5 & 2.0 & 151722.01 & 6910.13 & 246.59 & 843 & 852 & 63.50 & 17,597 & 16 \\
\hline \multirow[t]{18}{*}{75} & 3 & 0.2 & 158616.03 & time & 87.51 & 116 & 122 & 132.58 & 36,343 & 11 \\
\hline & 3 & 0.4 & 162688.30 & time & 96.27 & 128 & 136 & 286.56 & 55,479 & 18 \\
\hline & 3 & 0.6 & 166760.57 & time & 119.75 & 157 & 169 & 374.71 & 48,110 & 18 \\
\hline & 3 & 0.8 & 170832.83 & time & 108.09 & 144 & 152 & 268.94 & 36,734 & 10 \\
\hline & 3 & 1.0 & 174905.10 & time & 104.82 & 146 & 151 & 391.39 & 61,704 & 28 \\
\hline & 3 & 2.0 & 181884.48 & time & 115.25 & 176 & 180 & 262.15 & 50,051 & 13 \\
\hline & 4 & 0.2 & 143378.36 & time & 217.57 & 289 & 299 & 280.31 & 55,631 & 18 \\
\hline & 4 & 0.4 & 147155.22 & time & 229.61 & 302 & 316 & 303.98 & 50,264 & 19 \\
\hline & 4 & 0.6 & 150932.07 & time & 238.42 & 317 & 326 & 364.40 & 56,162 & 23 \\
\hline & 4 & 0.8 & 154708.93 & time & 253.93 & 340 & 351 & 461.78 & 49,790 & 21 \\
\hline & 4 & 1.0 & 158485.78 & time & 252.40 & 344 & 351 & 300.92 & 44,829 & 12 \\
\hline & 4 & 2.0 & 165109.53 & time & 244.89 & 366 & 376 & 309.91 & 48,873 & 18 \\
\hline & 5 & 0.2 & 133621.16 & time & 650.01 & 813 & 827 & 919.75 & 47,096 & 19 \\
\hline & 5 & 0.4 & 137394.13 & time & 695.39 & 874 & 883 & 254.12 & 41,254 & 13 \\
\hline & 5 & 0.6 & 141167.10 & time & 753.99 & 934 & 947 & 549.18 & 43,507 & 17 \\
\hline & 5 & 0.8 & 144940.08 & time & 833.32 & 1022 & 1032 & 570.64 & 53,242 & 17 \\
\hline & 5 & 1.0 & 148713.05 & time & 894.67 & 1097 & 1111 & 1192.06 & 55,431 & 24 \\
\hline & 5 & 2.0 & 155507.19 & time & 1014.41 & 1295 & 1304 & 605.26 & 45,319 & 19 \\
\hline
\end{tabular}

whereas Benders 2 is not able to solve one of them. Although the number of iterations is much smaller in Benders 2, still the number of Benders cuts added is extremely high compared to Benders 1. Benders 2 has the shortest solution times for all the instances and it is able to solve two instances for which Benders 1 stopped with gaps of $2.20 \%$ and $2.18 \%$. For the only instance for which both approaches failed to reach optimality, the finals gaps are $7.43 \%$ with Benders 1 and $0.49 \%$ for Benders 2. For these instances, adding multiple cuts clearly outperforms the approach where a single cut is added at each iteration. It is also interesting to note that decomposition approaches are faster than solving the compact formulation even for small instances. 
Table 12

Comparison of exact approaches for hybrid demand uncertainty - large AP instances.

\begin{tabular}{|c|c|c|c|c|c|c|c|c|c|c|}
\hline \multirow[b]{2}{*}{$n$} & \multirow[b]{2}{*}{$p$} & \multirow[b]{2}{*}{$\psi$} & \multicolumn{4}{|l|}{ Benders 1} & \multicolumn{4}{|l|}{ Benders 2} \\
\hline & & & $\begin{array}{l}\text { Best } \\
\text { upper bound }\end{array}$ & $\begin{array}{l}\text { CPU time } \\
\text { (gap) }\end{array}$ & $\begin{array}{l}\text { \# Cuts } \\
\text { added }\end{array}$ & $\begin{array}{l}\text { \# } \\
\text { Callbacks }\end{array}$ & $\begin{array}{l}\text { Best } \\
\text { upper bound }\end{array}$ & $\begin{array}{l}\text { CPU time } \\
\text { (gap) }\end{array}$ & $\begin{array}{l}\text { \# Cuts } \\
\text { added }\end{array}$ & $\begin{array}{l}\text { \# } \\
\text { Callbacks }\end{array}$ \\
\hline \multirow[t]{18}{*}{100} & 3 & 0.2 & 158994.51 & 266.28 & 158 & 164 & 158994.51 & 613.84 & 95,231 & 18 \\
\hline & 3 & 0.4 & 163006.54 & 286.83 & 171 & 177 & 163006.54 & 794.49 & 63,053 & 11 \\
\hline & 3 & 0.6 & 167018.57 & 363.24 & 208 & 222 & 167018.57 & 956.68 & 58,406 & 12 \\
\hline & 3 & 0.8 & 171030.60 & 329.37 & 194 & 201 & 171030.60 & 1810.63 & 84,255 & 15 \\
\hline & 3 & 1.0 & 175042.62 & 335.73 & 202 & 207 & 175042.62 & 1543.70 & 90,341 & 17 \\
\hline & 3 & 2.0 & 181994.20 & 331.32 & 217 & 225 & 181994.20 & 1253.26 & 84,163 & 13 \\
\hline & 4 & 0.2 & 144217.26 & 775.50 & 451 & 460 & 144217.26 & 2421.80 & 94,983 & 17 \\
\hline & 4 & 0.4 & 147958.05 & 777.60 & 452 & 461 & 147958.05 & 1481.09 & 105,415 & 25 \\
\hline & 4 & 0.6 & 151698.84 & 838.58 & 483 & 495 & 151698.84 & 1428.31 & 88,840 & 20 \\
\hline & 4 & 0.8 & 155439.64 & 902.40 & 518 & 530 & 155439.64 & 2241.51 & 132,278 & 39 \\
\hline & 4 & 1.0 & 159180.43 & 869.02 & 507 & 517 & 159180.43 & 1932.22 & 101,617 & 20 \\
\hline & 4 & 2.0 & 166020.92 & 895.31 & 568 & 583 & 166020.92 & 1354.11 & 90,833 & 21 \\
\hline & 5 & 0.2 & 135171.84 & 3335.92 & 1716 & 1725 & 135171.84 & 2680.25 & 102,190 & 22 \\
\hline & 5 & 0.4 & 138973.88 & 3769.12 & 1897 & 1906 & 138973.88 & 6385.78 & 100,316 & 21 \\
\hline & 5 & 0.6 & 142764.70 & 4227.88 & 2026 & 2039 & 142764.70 & 3482.66 & 86,521 & 18 \\
\hline & 5 & 0.8 & 146518.15 & 4689.46 & 2210 & 2222 & 146518.15 & 3844.03 & 105,163 & 23 \\
\hline & 5 & 1.0 & 150271.61 & 5794.66 & 2380 & 2396 & 150271.61 & 5963.45 & 99,574 & 19 \\
\hline & 5 & 2.0 & 157031.30 & 5717.20 & 2732 & 2743 & 157031.30 & 6479.52 & 134,770 & 38 \\
\hline \multirow[t]{18}{*}{125} & 3 & 0.2 & 159417.26 & 602.77 & 168 & 176 & 159417.26 & 3864.58 & 117,924 & 12 \\
\hline & 3 & 0.4 & 163452.67 & 624.23 & 177 & 184 & 163452.67 & 2535.40 & 136,126 & 15 \\
\hline & 3 & 0.6 & 167488.07 & 685.71 & 190 & 198 & 167488.07 & 3504.79 & 150,912 & 16 \\
\hline & 3 & 0.8 & 171523.48 & 700.98 & 200 & 202 & 171523.48 & 4964.69 & 176,865 & 24 \\
\hline & 3 & 1.0 & 175538.13 & 779.58 & 221 & 227 & 175538.13 & 9866.77 & 180,790 & 27 \\
\hline & 3 & 2.0 & 182590.08 & 767.05 & 237 & 245 & 182590.08 & 4695.79 & 195,335 & 24 \\
\hline & 4 & 0.2 & 144632.27 & 1807.48 & 504 & 515 & 144632.27 & 4242.95 & 145,345 & 17 \\
\hline & 4 & 0.4 & 148396.25 & 1827.44 & 506 & 521 & 148396.25 & 4193.69 & 207,417 & 28 \\
\hline & 4 & 0.6 & 152160.22 & 1931.55 & 541 & 551 & 152160.22 & 4711.28 & 168,262 & 25 \\
\hline & 4 & 0.8 & 155924.20 & 1977.29 & 551 & 563 & 155924.20 & 12664.45 & 207,851 & 34 \\
\hline & 4 & 1.0 & 159681.40 & 2078.27 & 571 & 584 & 159681.40 & 13821.47 & 150,987 & 24 \\
\hline & 4 & 2.0 & 166538.70 & 2130.83 & 649 & 661 & 166538.70 & 10433.65 & 212,734 & 35 \\
\hline & 5 & 0.2 & 135542.63 & 9681.35 & 1900 & 1912 & 135542.63 & 22826.78 & 178,238 & 29 \\
\hline & 5 & 0.4 & 139343.37 & 8937.65 & 2001 & 2012 & 139343.37 & 24590.05 & 146,195 & 18 \\
\hline & 5 & 0.6 & 143144.12 & 9801.77 & 2205 & 2222 & 143144.12 & 16461.26 & 169,122 & 22 \\
\hline & 5 & 0.8 & 146944.86 & 10986.91 & 2395 & 2401 & 146944.86 & 24385.10 & 138,443 & 19 \\
\hline & 5 & 1.0 & 150745.61 & 12202.34 & 2643 & 2656 & 150745.61 & 29901.92 & 224,433 & 40 \\
\hline & 5 & 2.0 & 157452.82 & 13971.64 & 3059 & 3073 & $157481.18 *$ & $(0.97)$ & 227,450 & 35 \\
\hline \multirow[t]{18}{*}{150} & 3 & 0.2 & 159983.60 & 1244.12 & 171 & 182 & 159983.60 & 5269.90 & 193,319 & 15 \\
\hline & 3 & 0.4 & 164032.32 & 1412.94 & 199 & 208 & 164032.32 & 22681.38 & 257,271 & 23 \\
\hline & 3 & 0.6 & 168081.04 & 1522.25 & 218 & 221 & 168081.04 & 15230.17 & 196,443 & 15 \\
\hline & 3 & 0.8 & 172129.76 & 1701.13 & 240 & 249 & 172129.76 & 20277.20 & 216,270 & 17 \\
\hline & 3 & 1.0 & 176178.48 & 1756.99 & 251 & 259 & $176178.48 *$ & (1.06) & 210,705 & 15 \\
\hline & 3 & 2.0 & 183335.89 & 1674.74 & 269 & 276 & $183335.89 *$ & $(0.72)$ & 306,489 & 27 \\
\hline & 4 & 0.2 & 145198.98 & 4088.74 & 585 & 596 & 145198.98 & 19923.08 & 219,854 & 17 \\
\hline & 4 & 0.4 & 148975.27 & 4572.64 & 648 & 663 & 148975.27 & 20134.93 & 221,218 & 22 \\
\hline & 4 & 0.6 & 152751.56 & 4361.46 & 607 & 620 & $152751.56 *$ & (16.22) & 300,320 & 33 \\
\hline & 4 & 0.8 & 156527.85 & 4651.64 & 650 & 665 & 156527.85 & 35125.56 & 316,005 & 33 \\
\hline & 4 & 1.0 & 160304.14 & 4900.01 & 695 & 709 & 160304.14 & 35840.99 & 292,375 & 25 \\
\hline & 4 & 2.0 & 167163.01 & 5001.49 & 784 & 796 & $167163.01 *$ & $(0.54)$ & 266,554 & 26 \\
\hline & 5 & 0.2 & 136037.51 & 20716.03 & 2169 & 2186 & $137205.61 *$ & (11.11) & 259,562 & 17 \\
\hline & 5 & 0.4 & 139833.66 & 21068.13 & 2300 & 2309 & $140087.65 *$ & $(1.36)$ & 315,885 & 29 \\
\hline & 5 & 0.6 & 143629.82 & 22197.72 & 2508 & 2520 & $143629.82 *$ & $(0.40)$ & 278,246 & 28 \\
\hline & 5 & 0.8 & 147425.97 & 25575.96 & 2720 & 2729 & $148260.76 *$ & $(1.50)$ & 314,151 & 27 \\
\hline & 5 & 1.0 & 151222.12 & 28342.47 & 2963 & 2975 & $151222.12 *$ & (2.96) & 292,740 & 31 \\
\hline & 5 & 2.0 & 158001.70 & 33081.89 & 3667 & 3681 & $158001.70 *$ & (11.52) & 278,170 & 26 \\
\hline
\end{tabular}

Tables 11 and 12 show the results of comparison between exact solution methods for the robust UMApHMP under hybrid demand uncertainty. The results obtained from small instances with up to 75 nodes are presented in Table 11 and the results for the larger ones with up to 150 nodes are in Table 12. For the instances with more than 50 nodes, the MIP formulation fails to find lower bounds within the time limit. All instances in Table 11 are solved to optimality by two Benders decomposition algorithms proposed. For the small instances with $n=40,50$ Benders 2 outperforms the others in terms of computational times. Considering instances with 75 nodes, Benders 1 performs better than Benders 2 for all except four instances with $p=5$. Again the number of cuts added in Benders 2 is higher than the number of cuts added in Benders 1 even though less number of iterations is performed by Benders 2 . 
The results in Table 12 indicate that Benders 1 outperforms Benders 2 in terms of solution times for large instances with hybrid demand uncertainty. Benders 1 is able to solve all of 54 instances whereas Benders 2 can not solve 11 of them. Considering all the results for the robust UMApHMP under hybrid demand uncertainty, we observe that Benders 1 tends to perform better as $n$ increases and $p$ decreases.

\section{Conclusions}

In this study, we introduced the robust multiple allocation $p$-hub median problems under hose and hybrid demand uncertainty sets. We presented compact mixed integer programming formulations and two Benders decomposition approaches to solve these problems. The results showed that keeping the dual variables in the master problem and adding multiple cuts works better with the hose model whereas moving the dual variables to the subproblem and adding a single cut at each iteration works better for large size instances with hybrid uncertainty.

When we examined the optimal solutions, we observed that the demand uncertainty does not result in big changes in the hub locations. The locations either remain the same or move to a close place. We believe that the reason for this is that when the hub locations are given, each commodity is routed on a shortest path from its origin to its destination regardless of the amount of demand. In summary, we observed that with minor changes in the hub network, one can hedge against uncertainty and obtain significant cost savings.

As future research, our aim is to incorporate demand uncertainty into different variants of the hub location problem using hose and hybrid models. The uncapacitated $p$-hub median problem has basic assumptions such as the hub network being complete, the discounts being independent of the amount of flow and the hubs being uncapacitated. In some instances, we observed that flows between two hub nodes are less than flows between non hub and hub nodes. Related with this, most of the flow in the network goes through a few hubs and the remaining hubs handle much less flow. Relaxing the assumptions on the network and discount structure and capacities may lead to more realistic problems. However, we expect the resulting problems to be more challenging.

\section{Acknowledgments}

The research of the first author is supported by the Scientific and Technological Research Council of Turkey and the research of the second author is supported by the Turkish Academy of Sciences.

\section{References}

Altın, A., Yaman, H., Pınar, M.Ç., 2011a. A hybrid polyhedral uncertainty model for the robust network loading problem. In: Performance Models and Risk Management in Communications Systems. Springer, pp. 157-172.

Altın, A., Yaman, H., Pınar, M.C., 2011b. The robust network loading problem under hose demand uncertainty: formulation, polyhedral analysis, and computations. INFORMS Journal on Computing 23 (1), 75-89.

Alumur, S.A., Kara, B.Y., 2008. Network hub location problems: the state of the art. European Journal of Operational Research 190 (1), 1-21.

Alumur, S.A., Kara, B.Y., Karasan, O.E., 2009. The design of single allocation incomplete hub networks. Transportation Research Part B: Methodological 43 (10), 936-951.

Alumur, S.A., Nickel, S., da Gama, F.S., 2012. Hub location under uncertainty. Transportation Research Part B: Methodological 46 (4), $529-543$.

Alumur, S.A., Yaman, H., Kara, B.Y., 2012. Hierarchical multimodal hub location problem with time-definite deliveries. Transportation Research Part E: Logistics and Transportation Review 48 (6), 1107-1120.

An, Y., Zhang, Y., Zeng, B., 2015. The reliable hub-and-spoke design problem: models and algorithms. Transportation Research Part B: Methodological 77, $103-122$.

Atamtürk, A., 2006. Strong formulations of robust mixed 0-1 programming. Mathematical Programming 108 (2-3), 235-250.

Ben-Tal, A., Goryashko, A., Guslitzer, E., Nemirovski, A., 2004. Adjustable robust solutions of uncertain linear programs. Mathematical Programming 99 (2), 351-376.

Ben-Tal, A., Nemirovski, A., 1998. Robust convex optimization. Mathematics of Operations Research 23 (4), 769-805.

Ben-Tal, A., Nemirovski, A., 1999. Robust solutions of uncertain linear programs. Operations Research Letters 25 (1), 1-13.

Ben-Tal, A., Nemirovski, A., 2008. Selected topics in robust convex optimization. Mathematical Programming 112 (1), $125-158$.

Benders, J.F., 1962. Partitioning procedures for solving mixed-variables programming problems. Numerische Mathematik 4 (1), 238-252.

Bertsimas, D., Sim, M., 2003. Robust discrete optimization and network flows. Mathematical Programming 98 (1-3), 49-71.

Bertsimas, D., Sim, M., 2004. The price of robustness. Operations Research 52 (1), 35-53.

Bhadra, D., 2003. Demand for air travel in the united states: bottom-up econometric estimation and implications for forecasts by origin and destination pairs. Journal of Air Transportation 8 (2), 19-56.

Boland, N., Krishnamoorthy, M., Ernst, A.T., Ebery, J., 2004. Preprocessing and cutting for multiple allocation hub location problems. European Journal of Operational Research 155 (3), 638-653.

Calık, H., Alumur, S.A., Kara, B.Y., Karasan, O.E., 2009. A tabu-search based heuristic for the hub covering problem over incomplete hub networks. Computers \& Operations Research 36 (12), 3088-3096.

Camargo, R., d. MirandaJr., G., Luna, H.P., 2008. Benders decomposition for the uncapacitated multiple allocation hub location problem. Computers \& Operations Research 35 (4), 1047-1064.

Camargo, R., d. MirandaJr., G., Luna, H.P., 2009. Benders decomposition for hub location problems with economies of scale. Transportation Science 43 (1), $86-97$.

d. Camargo, R.S., de Miranda Jr, G., Luna, H.P.L., 2009. Benders decomposition for hub location problems with economies of scale. Transportation Science 43 (1), 86-97.

Campbell, J.F., 1992. Location and allocation for distribution systems with transshipments and transportion economies of scale. Annals of Operations Research 40 (1), 77-99.

Campbell, J.F., 1994. Integer programming formulations of discrete hub location problems. European Journal of Operational Research 72 (2), $387-405$.

Campbell, J.F., 1994. A survey of network hub location. Studies in Locational Analysis 6, 31-49.

Campbell, J.F., 1996. Hub location and the p-hub median problem. Operations Research 44 (6), $923-935$. 
Campbell, J.F., Ernst, A.T., Krishnamoorthy, M., 2002. Hub location problems. Facility location: applications and theory 1, $373-407$.

Campbell, J.F., Ernst, A.T., Krishnamoorthy, M., 2005a. Hub arc location problems: part i introduction and results. Management Science 51 (10), $1540-1555$.

Campbell, J.F., Ernst, A.T., Krishnamoorthy, M., 2005b. Hub arc location problems: part ii formulations and optimal algorithms. Management Science 51 (10), 1556-1571.

Campbell, J.F., O’Kelly, M.E., 2012. Twenty-five years of hub location research. Transportation Science 46 (2), $153-169$.

Cánovas, L., García, S., Marín, A., 2007. Solving the uncapacitated multiple allocation hub location problem by means of a dual-ascent technique. European Journal of Operational Research 179 (3), 990-1007.

Contreras, I., Cordeau, J.-F., Laporte, G., 2011a. Benders decomposition for large-scale uncapacitated hub location. Operations Research 59 (6), 1477-1490.

Contreras, I., Cordeau, J.-F., Laporte, G., 2011b. Stochastic uncapacitated hub location. European Journal of Operational Research 212 (3), 518-528.

Contreras, I., Fernández, E., Marín, A., 2010. The tree of hubs location problem. European Journal of Operational Research 202 (2), $390-400$.

Correia, I., Nickel, S., Saldanha-da Gama, F., 2010. Single-assignment hub location problems with multiple capacity levels. Transportation Research Part B: Methodological 44 (8), 1047-1066.

Duffield, N.G., Goyal, P., Greenberg, A., Mishra, P., Ramakrishnan, K.K., van der Merive, J.E., 1999. A flexible model for resource management in virtual private networks. In: ACM SIGCOMM Computer Communication Review, vol. 29. ACM, pp. 95-108.

Ebery, J., Krishnamoorthy, M., Ernst, A.T., Boland, N., 2000. The capacitated multiple allocation hub location problem: formulations and algorithms. European Journal of Operational Research 120 (3), 614-631.

Ernst, A.T., Krishnamoorthy, M., 1996. Efficient algorithms for the uncapacitated single allocation p-hub median problem. Location science 4 (3), 139-154.

Ernst, A.T., Krishnamoorthy, M., 1998a. Exact and heuristic algorithms for the uncapacitated multiple allocation $p$-hub median problem. European Journal of Operational Research 104 (1), 100-112.

Ernst, A.T., Krishnamoorthy, M., 1998b. An exact solution approach based on shortest-paths for p-hub median problems. INFORMS Journal on Computing 10 (2), 149-162.

Farahani, R.Z., Hekmatfar, M., Arabani, A.B., Nikbakhsh, E., 2013. Hub location problems: a review of models, classification, solution techniques, and applications. Computers \& Industrial Engineering 64 (4), 1096-1109.

Fingerhut, J.A., Suri, S., Turner, J.S., 1997. Designing least-cost nonblocking broadband networks. Journal of Algorithms 24 (2), 287-309.

Gelareh, S., Nickel, S., 2011. Hub location problems in transportation networks. Transportation Research Part E: Logistics and Transportation Review 47 (6), 1092-1111.

Hamacher, H.W., Labbé, M., Nickel, S., Sonneborn, T., 2004. Adapting polyhedral properties from facility to hub location problems. Discrete Applied Mathematics 145 (1), 104-116.

Horner, M.W., O’Kelly, M.E., 2001. Embedding economies of scale concepts for hub network design. Journal of Transport Geography 9 (4), $255-265$.

Hsiao, C.-Y., Hansen, M., 2011. A passenger demand model for air transportation in a hub-and-spoke network. Transportation Research Part E: Logistics and Transportation Review 47 (6), 1112-1125.

Klincewicz, J.G., 1996. A dual algorithm for the uncapacitated hub location problem. Location Science 4 (3), $173-184$.

Klincewicz, J.G., 1998. Hub location in backbone/tributary network design: a review. Location Science 6 (1), $307-335$.

Labbé, M., Yaman, H., 2008. Solving the hub location problem in a star-star network. Networks 51 (1), 19-33.

Marianov, V., Serra, D., 2003. Location models for airline hubs behaving as m/d/c queues. Computers \& Operations Research 30 (7), $983-1003$.

Marín, A., 2005. Uncapacitated euclidean hub location: strengthened formulation, new facets and a relax-and-cut algorithm. Journal of Global Optimization 33 (3), 393-422.

Mayer, G., Wagner, B., 2002. Hublocator: an exact solution method for the multiple allocation hub location problem. Computers \& Operations Research 29 (6), 715-739.

Mudchanatongsuk, S., Ordóñez, F., Liu, J., 2008. Robust solutions for network design under transportation cost and demand uncertainty. Journal of the Operational Research Society 59 (5), 652-662.

Nickel, S., Schöbel, A., Sonneborn, T., 2001. Hub location problems in urban traffic networks. In: Mathematical methods on optimization in transportation systems. Springer, pp. 95-107.

O'Kelly, M.E., 1987. A quadratic integer program for the location of interacting hub facilities. European Journal of Operational Research 32 (3), 393-404.

O'Kelly, M.E., Bryan, D.L., 1998. Hub location with flow economies of scale. Transportation Research Part B: Methodological 32 (8), 605-616.

O'Kelly, M.E., Campbell, J.F., Camargo, R.S.d., Miranda, G., 2015. Multiple allocation hub location model with fixed arc costs. Geographical Analysis 47 (1), 73-96.

O’Kelly, M.E., Miller, H.J., 1994. The hub network design problem: a review and synthesis. Journal of Transport Geography 2 (1), $31-40$.

OR-Library, 2015.

Ordóñez, F., Zhao, J., 2007. Robust capacity expansion of network flows. Networks 50 (2), 136-145.

Podnar, H., Skorin-Kapov, J., Skorin-Kapov, D., 2002. Network cost minimization using threshold-based discounting. European Journal of Operational Research 137 (2), 371-386.

Shahabi, M., Unnikrishnan, A., 2014. Robust hub network design problem. Transportation Research Part E: Logistics and Transportation Review $70,356-373$.

Sim, T., Lowe, T.J., Thomas, B.W., 2009. The stochastic p-hub center problem with service-level constraints. Computers \& Operations Research 36 (12), 3166-3177.

Skorin-Kapov, D., Skorin-Kapov, J., O’Kelly, M., 1996. Tight linear programming relaxations of uncapacitated p-hub median problems. European Journal of Operational Research 94 (3), 582-593.

Yaman, H., 2008. Star p-hub median problem with modular arc capacities. Computers \& Operations Research 35 (9), $3009-3019$.

Yaman, H., 2009. The hierarchical hub median problem with single assignment. Transportation Research Part B: Methodological 43 (6), $643-658$.

Yaman, H., 2011. Allocation strategies in hub networks. European Journal of Operational Research 211 (3), 442-451.

Yaman, H., Elloumi, S., 2012. Star p-hub center problem and star p-hub median problem with bounded path lengths. Computers \& Operations Research 39 (11), 2725-2732.

Yaman, H., Karașan, O.E., Pınar, M.Ç., 2001. The robust spanning tree problem with interval data. Operations Research Letters 29 (1), 31-40.

Yaman, H., Kara, B.Y., Tansel, B.Ç., 2007a. The latest arrival hub location problem for cargo delivery systems with stopovers. Transportation Research Part B: Methodological 41 (8), 906-919.

Yaman, H., Karaşan, O.E., Pınar, M.Ç., 2007b. Restricted robust uniform matroid maximization under interval uncertainty. Mathematical Programming 110 (2), 431-441.

Yang, T.-H., 2009. Stochastic air freight hub location and flight routes planning. Applied Mathematical Modelling 33 (12), $4424-4430$.

Yoon, M.-G., Current, J., 2008. The hub location and network design problem with fixed and variable arc costs: formulation and dual-based solution heuristic. Journal of the Operational Research Society 59 (1), 80-89. 